\title{
The effect of morphology upon electrophysiological responses of retinal ganglion cells: simulation results
}

\author{
Matias I. Maturana • Tatiana Kameneva • \\ Anthony N. Burkitt • Hamish Meffin . \\ David B. Grayden
}

Received: 12 October 2012 / Revised: 15 April 2013 / Accepted: 14 May 2013 / Published online: 9 July 2013

(C) The Author(s) 2013. This article is published with open access at Springerlink.com

\begin{abstract}
Retinal ganglion cells (RGCs) display differences in their morphology and intrinsic electrophysiology. The goal of this study is to characterize the ionic currents that explain the behavior of ON and OFF RGCs and to explore if all morphological types of RGCs exhibit the phenomena described in electrophysiological data. We extend our previous single compartment cell models of ON and OFF RGCs to more biophysically realistic multicompartment cell models and investigate the effect of cell morphology on intrinsic electrophysiological properties. The membrane dynamics are described using the Hodgkin Huxley type formalism. A subset of published patch-clamp data from isolated intact mouse retina is used to constrain the model and another subset is used to validate the model. Two hundred morphologically distinct ON and OFF RGCs are simulated with various densities of ionic currents in different morphological neuron compartments. Our model predicts that the differences between $\mathrm{ON}$ and OFF cells are explained by the presence of the low voltage activated calcium current in OFF cells and absence of such in ON
\end{abstract}

\section{Action Editor: John Huguenard}

M. I. Maturana - T. Kameneva ( $\triangle)$ - A. N. Burkitt · H. Meffin ·

D. B. Grayden

Centre for Neural Engineering, University of Melbourne,

203 Bouverie St, Carlton, Vic 3053, Australia

e-mail: tkam@unimelb.edu.au

T. Kameneva · A. N. Burkitt · H. Meffin · D. B. Grayden NICTA Victoria Research Laboratory, Department Electrical \& Electronic Engineering, University of Melbourne, Lvl 2, Bld 193, Melbourne, Vic 3010, Australia

A. N. Burkitt - D. B. Grayden

Bionics Institute, 384-388 Albert St. East Melbourne, Melbourne, Vic 3002, Australia cells. Our study shows through simulation that particular morphological types of RGCs are capable of exhibiting the full range of phenomena described in recent experiments. Comparisons of outputs from different cells indicate that the RGC morphologies that best describe recent experimental results are ones that have a larger ratio of soma to total surface area.

Keywords Retinal ganglion cells · Retina $\cdot$ Ion channels physiology $\cdot$ Models $\cdot$ Neurophysiology ·

Multicompartment modelling

\section{Introduction}

Photoreceptor cells convert light energy into signals that are transmitted to bipolar cells. Bipolar cells are divided into two types that respond to either increments or decrements in light intensity. Consequently, the signals from photoreceptors are divided into two pathways, the so called $\mathrm{ON}$ and OFF pathways. ON and OFF pathways converge at the level of simple cells in the visual cortex.

Retinal ganglion cells (RGCs) are the sole output neurons of the retina. They convert synaptic input from bipolar and other types of inner retinal neurons into signals that carry visual information to the brain. RGCs that respond with increasing spiking frequency to light increments are called ON RGCs. RGCs that increase their spiking frequency with light decrements are called OFF RGCs. OFF-transient cells (OFF T RGCs) are quiet in darkness and have transient spikes at light offset. OFF-sustained cells (OFF S RGCs) fire spontaneous spikes in darkness and have a sustained component of spiking activity during light illumination showed by Murphy and Rieke (2006) and Pang et al. (2003). ON and OFF RGCs can be distinguished 
not only by their response to light but also by their morphology. In particular, while both ON and OFF RGC somas are located in the retinal ganglion cell layer of the retina, the dendrites of OFF RGCs stratify within sublamina $a$ of the inner plexiform layer, while ON cell dendrites stratify within sublamina $b$ (Nelson et al. 1978).

Neurons operate in a highly nonlinear manner, generating oscillations and bursting phenomena, thus potentially enhancing the information content of the transmitted signal. RGCs are no exception. It has been shown that OFF RGCs maintain spontaneous activity in the absence of any synaptic input and exhibit subthreshold membrane potential oscillations, rebound excitation and burst firing. On the other hand, ON cells do not show the aforementioned phenomena and require excitatory synaptic input to drive their activity (Margolis and Detwiler 2007).

In an attempt to understand the mechanisms underlying burst firing and subthreshold oscillation in RGCs, a number of studies have examined the voltage-gated channels underlying these phenomena. Rebound excitation is a volley of action potentials at the termination of a period of sustained hyperpolarization. Subthreshold membrane potential oscillations are rhythmic fluctuations in membrane potential that do not result in action potentials. Mechanisms underlying rebound excitation in RGCs were investigated by Mitra and Miller (2007), who showed that low-voltage-activated (LVA) $\mathrm{Ca}^{2+}$ and hyperpolarization-activated currents are the main generators of rebound excitation. The availability of LVA $\mathrm{Ca}^{2+}$ current in RGCs was also shown by Lee et al. (2003) and Henderson and Miller (2007), while experimental evidence that the hyperpolarization-activated current is present in RGCs was also shown by Lee and Ishida (2007) and Chen and Yang (2007). The role of the persistent sodium current in burst activity was elucidated by van Drongelen et al. (2006) and Traub et al. (2003) who showed the persistent sodium current contributes to fast rhythmic bursting due to its low activation threshold and limited inactivation.

Rebound excitation and subthreshold oscillation were also observed in thalamic neurons (Llinas and Steriade 2006). Similar to RGCs, these phenomena in thalamic neurons were related to LVA $\mathrm{Ca}^{2+}$ and hyperpolarizationactivated currents. Similarly, it was shown that LVA $\mathrm{Ca}^{2+}$ current plays a triggering role in rebound excitation in neurons in the central nervous system (Huguenard 1996). The depolarization of the membrane potential at the termination of a hyperpolarization step opens LVA $\mathrm{Ca}^{2+}$ channels producing strong inward $\mathrm{Ca}^{2+}$ current that triggers a low threshold calcium spike and a burst of fast and large amplitude sodium action potentials. It was shown that the same current underlies burst generation of thalamocortical relay neurons and plays a central role in the genesis of synchronized oscillations by thalamic cells (Destexhe et al.
1998). In these neurons, the authors showed that LVA $\mathrm{Ca}^{2+}$ channels in dendrites must be 4.5-7.6 times higher concentration than in the soma to reproduce experimental results.

Dendritic calcium signaling in ON and OFF RGCs was examined by Margolis et al. (2010). Using simultaneous patch-clamp recordings and two-photon $\mathrm{Ca}^{2+}$ imaging, the authors showed pathway-specific differences in voltagedependent $\mathrm{Ca}^{2+}$ signaling. In particular, it was shown that, while both ON and OFF RGCs express high-voltage activated $\mathrm{Ca}^{2+}$ current, only OFF cells express LVA $\mathrm{Ca}^{2+}$ channels. This result was supported by an earlier study by Guenther et al. (1999), who showed that only a subset of RGCs expressed LVA Ca ${ }^{2+}$ channels.

Computational models provide a formal description of biological processes. Such models serve an important role in testing ideas that are difficult to test experimentally. Computational models can provide detailed realizations of biological systems and processes, suggest experiments in areas that are not well understood, and make specific predictions about cell behaviors. Using compartmental cell models representing simplified RGC morphology, Schiefer and Grill (2006) investigated the effect of an axonal bend on activation threshold, showing that low excitation thresholds near the bend in the axon results in activation of the cells local to the electrode at lower currents than required to excite passing axons. However, the existence of the axonal high density sodium channel band (SOCB) in RGCs was not taken into account in their study. When SOCB properties were taken into account, Jeng et al. (2011) showed that the lowest activation threshold for extracellular electrical stimulation is when the stimulating electrode is placed exactly over the physical location of the SOCB. This computational study agrees well with the experimental results of Fried et al. (2009) who conclude that the action potential initiation site in response to electrical stimulation is in the SOCB. Benison et al. (2001) examined the effect of intracellular calcium diffusion on the amplitude and shape of individual spikes as well as spiking frequency in postnatal cat RGCs. They showed that the diffusion of intracellular $\mathrm{Ca}^{2+}$ modeled spatially rather than averaged across the whole cell, was more effective in gating $\mathrm{Ca}$-activated potassium currents. Mechanisms by which cell geometry influences repetitive impulse firing in RGCs were investigated in Fohlmeister and Miller (1997) and found that intercompartmental currents play a major role in determining the impulse spacing and information carried by impulse trains.

Computational modeling was carried out on cell models to explore the effects of ON and OFF RGCs' morphologies on their intrinsic electrophysiological properties. Although Margolis and Detwiler (2007) explored only mouse $\alpha$-RGCs, we explore 200 cells of different types and morphologies to determine which morphological types can 
reproduce responses similar to $\alpha$-RGCs. We propose that not all morphological types of RGCs exhibit the phenomena described by Margolis and Detwiler (2007) and show that this is supported by simulations. In this study, we extend our previous single compartment cell model (Kameneva et al. 2011) to more biophysically realistic multicompartment cell models and investigate the effect of cell morphology on intrinsic electrophysiological properties.

\section{Methods}

\subsection{Cell morphology}

In order to examine the effect of morphology upon the intrinsic electrophysiological response of RGCs, simulations were carried out with two hundred different multicompartment RGC models. Each cell varied in soma and dendrite lengths and diameters, and in dendritic branching structure. Multicompartment RGC structures were taken from the NeuroMorpho database (Ascoli et al. 2007). The cells were divided into two groups: 144 mouse RGCs (Coombs et al. 2006) and 56 salamander RGCs (Toris et al. 1995). Salamander RGCs have long been used in retinal electrophysiological experiments and the $\alpha$-RGCs show similarities in morphology to the mouse A cells (Sun et al. 2002). Although experiments were conducted on mouse cells, simulations using similar types of salamander cells allow the exploration of a larger range of morphologies that can produce $\alpha$-RGC-like behavior. Examples illustrated in Fig. 1 are created using NEURON (Hines 1993). The cells in Fig. 1a-c show cell models that have a large soma and dendrites that have decreasing diameters. Figure $1 \mathrm{~d}-\mathrm{f}$ show cell models that have small to medium sized soma and generally uniform diameter dendrites. While model tuning and validation were based on mouse A type RGCs, it is unclear what the morphological types of the mouse and salamander cells are in the NeuroMorpho database. Most likely they contain a variety of cells from different morphological classes.

The cell models were divided into compartments representing the dendrites, soma, and axon as illustrated in Fig. 2. In all cells, the axon comprised four regions: the initial segment, sodium channel band (SOCB), narrow segment, and distal axon. The initial segment refers to the proximal portion of the axon that stems from the soma. This segment was of uniform diameter equal to the diameter of the distal axon. The narrow segment connects to the initial segment $40 \mu \mathrm{m}$ from the soma and extends for $90 \mu \mathrm{m}$. The narrow segment was modeled as a cylinder with uniform diameter of $0.4 \mu \mathrm{m}$, consistent with proportions used by Toris et al. (1995). The SOCB refers to a region comprising the distal part of the initial segment and the proximal part of the narrow region. This region was located $30 \mu \mathrm{m}$ proximal to the soma and extended $40 \mu \mathrm{m}$. This region had a higher concentration of sodium and persistent sodium channels. The distal axon had a diameter of $1 \mu \mathrm{m}$ and a fixed length of $5340 \mu \mathrm{m}$ for all cells. This is consistent with dimensions used in all salamander cells (Toris et al. 1995). The morphologies of the mouse cells in the NeuroMorpho database did not include an axon or included only a very short axon. In order to monitor action potential propagation in the axon and to allow consistency between the cell types, the mouse morphologies were modified to include the four axonal compartments described above.

The morphological properties of the cells are summarized in Table 1. All cell models have unique morphologies apart from the axon. For all cells, the total surface area, $S_{\text {total }}$, soma surface area, $S_{\text {soma }}$, axon surface area, $S_{\text {axon }}$, axon diameter, $D_{\text {axon }}$, and average dendrite diameter, $D_{\text {dendrite, }}$, were calculated for comparison. The ratios of dendrite to total surface area, $R_{\text {dend,total }}$, and soma to total surface area, $R_{\text {soma,total, }}$ were also computed. In addition, the number of dendritic tips (end of a dendritic branch), number of dendritic bifurcations, and average dendritic compartment lengths were also recorded. Cell surfaces areas were calculated by summing the surface area of the individual cylindrical compartments, omitting the end faces. In order to differentiate the unique cell properties, the total surface area excluded the axon.

\subsection{Model parameters}

Cells responses were simulated in the NEURON environment (Hines 1993). The membrane properties were described using Hodgkin-Huxley type equations and included leak $\left(I_{\mathrm{L}}\right)$, sodium $\left(I_{\mathrm{Na}}\right)$, calcium $\left(I_{\mathrm{Ca}}\right)$, delayed rectifier potassium $\left(I_{\mathrm{K}}\right)$, A-type $\left(I_{\mathrm{K}, \mathrm{A}}\right)$, and Ca-activated potassium $\left(I_{\mathrm{Ca}}\right)$ currents. The conductances of these currents remained fixed during simulations. T-type low voltage activated (LVA) calcium $\left(I_{\mathrm{T}}\right)$, hyperpolarization-activated $\left(I_{\mathrm{h}}\right)$, and sodium persistent $\left(I_{\mathrm{NaP}}\right)$ currents were also introduced and allowed to vary to explore the effects of these currents on the cells' responses. Simulations involved systematic parameter searches for the maximal ionic conductances of sodium persistent, $\bar{g}_{\mathrm{NaP}}$, T-type LVA calcium, $\bar{g}_{\mathrm{T}}$, and hyperpolarization-activated, $\bar{g}_{\mathrm{h}}$, conductances satisfying experimental data.

The RGC ionic currents were summed using Kirchoff's law,

$$
\begin{aligned}
C_{\mathrm{m}} \frac{d V}{d t}= & \bar{g}_{\mathrm{L}}\left(V-V_{\mathrm{L}}\right)+\bar{g}_{\mathrm{Na}} m^{3} h\left(V-V_{\mathrm{Na}}\right) \\
& +\bar{g}_{\mathrm{Ca}} c^{3}\left(V-V_{\mathrm{Ca}}\right)+\left(\bar{g}_{\mathrm{K}} n^{4}+\bar{g}_{\mathrm{K}, \mathrm{A}} a^{3} h_{\mathrm{A}}\right. \\
& \left.+\bar{g}_{\mathrm{K}(\mathrm{Ca})}\right)\left(V-V_{\mathrm{K}}\right)+\bar{g}_{\mathrm{h}} l\left(V-V_{\mathrm{h}}\right)+\bar{g}_{\mathrm{T}} m_{\mathrm{T}}^{3} h_{\mathrm{T}} \\
& \times\left(V-V_{\mathrm{T}}\right)+\bar{g}_{\mathrm{NaP}} p\left(V-V_{\mathrm{Na}}\right)+I_{\mathrm{stim}},
\end{aligned}
$$


Fig. 1 Plots of representative simulated RGC morphologies. Cells show different dendritic structures and soma sizes and shapes. a-c show cells that met model constraints, while $\mathbf{d}-\mathbf{f}$ show cells that did not meet constraints (see Section 2.3). All cell figures were compiled using NEURON (Hines 1993) and adapted from the NeuroMorpho database (Ascoli et al. 2007; Coombs et al. 2006; Toris et al. 1995)

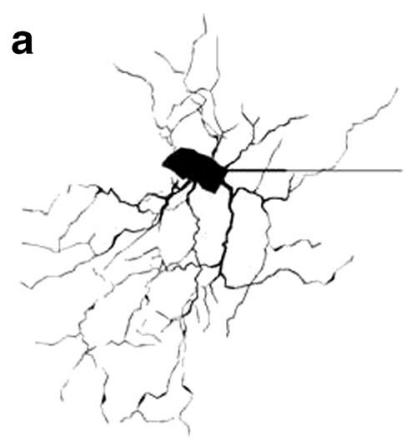

b

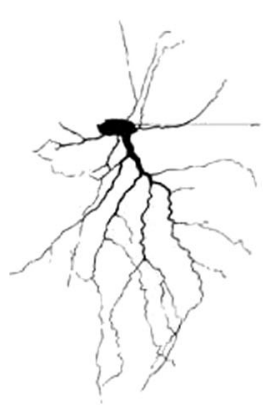

C
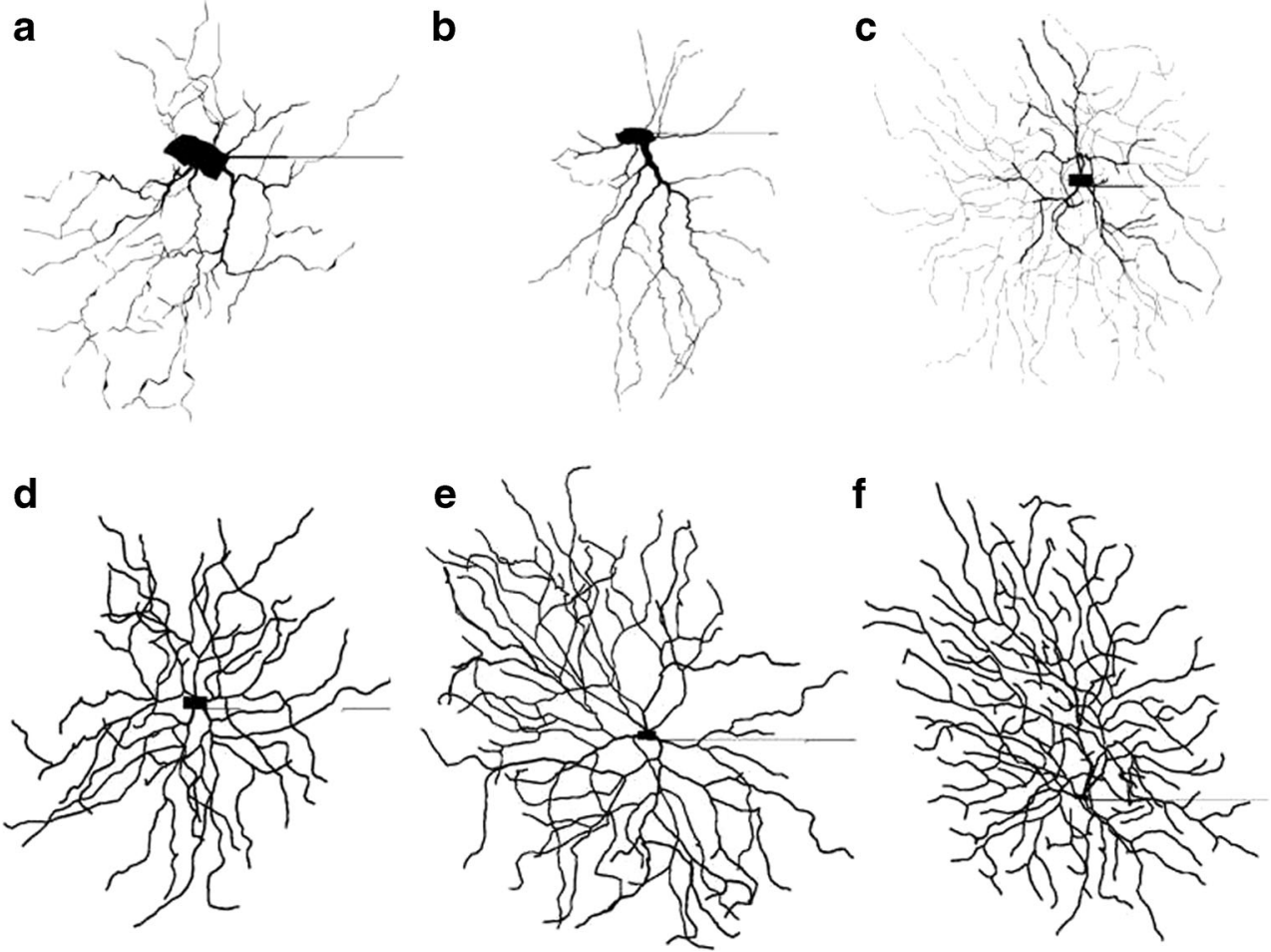

where $V$ is the membrane potential, $C_{\mathrm{m}}$ is the specific capacitance of the membrane, and $\bar{g}$ is the maximum conductance of the ionic current defined by the subscript. Leak, sodium, calcium, delayed rectifier potassium, A-type, and Ca-activated potassium currents have dynamics as described by Fohlmeister and Miller (1997). The hyperpolarizationactivated, T-type LVA calcium, and sodium persistent currents were modeled as by van Welie et al. (2006) and Wang et al. (1991) and Traub et al. (2003), respectively. $I_{\text {stim }}$ is an intracellular stimulation current. Since the data of Margolis and Detwiler (2007) was obtained under synaptic blockage, we did not include synaptic currents in the model.

In contrast to sodium and potassium ions, the normal intracellular calcium ion concentration is so low that it can be increased dramatically during a single depolarization response. At rest, the cytoplasmic free calcium level is between 20 and $300 \mathrm{nM}$. Since calcium replenishment operates by a different mechanism than other ions, involving intracellular calcium storage rather than transmembrane ion pumps, the calcium reversal potential varied with time according to

$$
V_{\mathrm{Ca}}(t)=\frac{R T}{2 F} \ln \left(\frac{\left[\mathrm{Ca}^{2+}\right]_{\mathrm{e}}}{\left[\mathrm{Ca}^{2+}\right]_{\mathrm{i}}(t)}\right),
$$

where $R$ is the gas constant, $T$ is temperature in Kelvin, $F$ is the Faraday constant, and $\left[\mathrm{Ca}^{2+}\right]_{\mathrm{e}}$ represents the extracellular calcium ion concentration in normal Ringer's solution. The intracellular calcium ion concentration $\left[\mathrm{Ca}^{2+}\right]_{\mathrm{i}}$ varied
Fig. 2 A schematic diagram of the cylinder model of a cell's morphology used in simulations. Compartments are represented by cylindrical elements. Soma and dendrite morphology (influencing the cylinders' lengths and diameters) varied from cell to cell. The morphology of the axon was the same for all cells

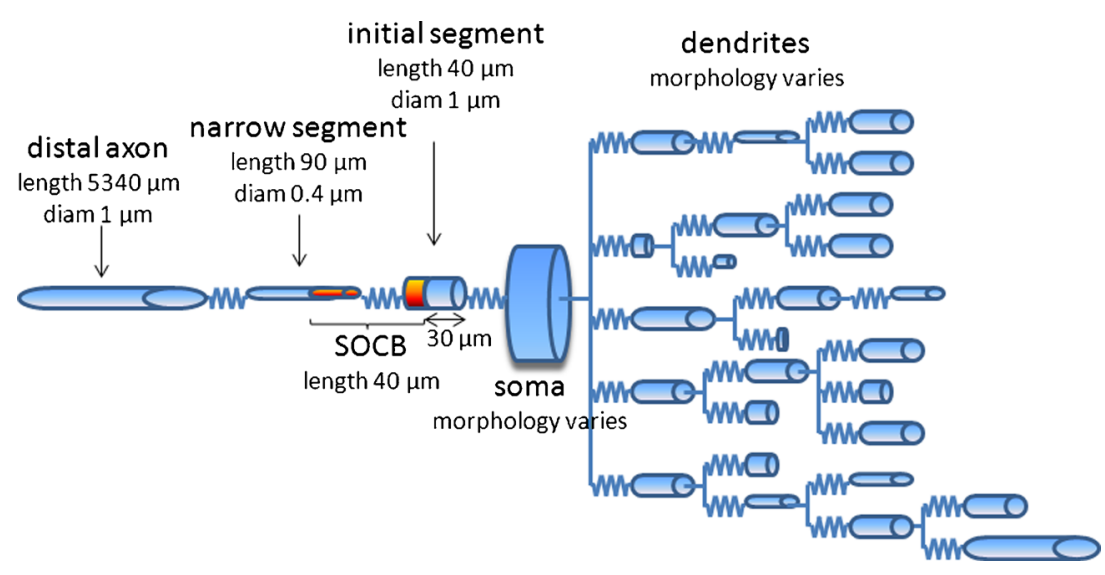


Table 1 Explored cells morphological statistics (200 cells in total). Cells taken from the NeuroMorpho database (Ascoli et al. 2007). Shown are the cell's minimum (Min), maximum (Max), average (Ave) and standard deviation (St Dev) values

\begin{tabular}{|c|c|c|c|c|c|c|}
\hline & $S_{\text {total }}$ & $S_{\text {soma }}$ & $S_{\text {axon }}$ & $S_{\text {dendrite }}$ & $D_{\text {axon }}$ & $D_{\text {dendrite }}$ \\
\hline & Total & Soma & Axon & Dendrite & Axon & Average \\
\hline & surface area & surface area & surface area & surface area & diameter & dendrite \\
\hline & & & & & & diameter \\
\hline & $\mu \mathrm{m}^{2}$ & $\mu \mathrm{m}^{2}$ & $\mu \mathrm{m}^{2}$ & $\mu \mathrm{m}^{2}$ & $\mu \mathrm{m}$ & $\mu \mathrm{m}$ \\
\hline Min & 969 & 10 & 17020 & 292 & 1 & 0.09 \\
\hline Max & 32457 & 2196 & 17020 & 31773 & 1 & 2.18 \\
\hline Ave & 9099 & 488 & 17020 & 8613 & 1 & 0.78 \\
\hline \multirow[t]{7}{*}{ St Dev } & 6004 & 425 & 0 & 6089 & 0 & 0.37 \\
\hline & & $R_{\text {dend,total }}$ & $R_{\text {soma,total }}$ & & & \\
\hline & Number of & Dendrite to total & Soma to total & Number of & Average & \\
\hline & dendritic tips & surface area & surface area & bifurcations & dendritic & \\
\hline & & ratio & ratio & & compartment & \\
\hline & & & & & length & \\
\hline & & & & & $\mu \mathrm{m}$ & \\
\hline Min & 7 & 0.30 & 0.0005 & 13 & 8 & \\
\hline Max & 377 & 0.99 & 0.70 & 754 & 142 & \\
\hline Ave & 62 & 0.90 & 0.10 & 123 & 42 & \\
\hline St Dev & 44 & 0.14 & 0.14 & 88 & 26 & \\
\hline
\end{tabular}

in response to $I_{\mathrm{Ca}}$ (the calcium current, the third term on the right of Eq. (1) according to Fohlmeister and Miller (1997)

$\frac{d\left[\mathrm{Ca}^{2+}\right]_{\mathrm{i}}(t)}{d t}=\frac{-3 I_{\mathrm{Ca}}(t)}{2 F r}-\frac{\left[\mathrm{Ca}^{2+}\right]_{\mathrm{i}}(t)-\left[\mathrm{Ca}^{2+}\right]_{\mathrm{res}}}{\tau_{\mathrm{Ca}}}$,

where $r=0.1 \mu \mathrm{m}$ is the depth of the shell beneath the membrane for the calcium pump and $\tau_{\mathrm{Ca}}=1.5 \mathrm{~ms}$ is the time constant for the calcium current. The free intracellular calcium ions above the residual level, $\left[\mathrm{Ca}^{2+}\right]_{\text {res }}=0.1 \mu \mathrm{M}$, are removed from the cell. At rest, $V_{\mathrm{Ca}}$ is approximately $120 \mathrm{mV}$.

The conductance of the Ca-activated potassium channels was modeled as

$\bar{g}_{\mathrm{K}(\mathrm{Ca})}(t)=g_{\mathrm{K}(\mathrm{Ca})} \cdot \frac{\left(\left[\mathrm{Ca}^{2+}\right]_{\mathrm{i}}(t) /\left(\mathrm{Ca}^{2+}\right)_{\mathrm{diss}}\right)^{2}}{1+\left(\left[\mathrm{Ca}^{2+}\right]_{\mathrm{i}}(t) /\left[\mathrm{Ca}^{2+}\right]_{\mathrm{diss}}\right)^{2}}$,

where $g_{\mathrm{K}(\mathrm{Ca})}=5 \cdot 10^{-5} \mathrm{~S} / \mathrm{cm}^{2}$ and $\left[\mathrm{Ca}^{2+}\right]_{\text {diss }}=10^{-6}$ is the calcium dissociation constant.

The numerical values for the parameters used in simulations are given in Table 2. The experimental data used to constrain and validate our model was obtained at 30$34{ }^{\circ} \mathrm{C}$. Therefore, simulations were run at $32{ }^{\circ} \mathrm{C}$. The gating variables $m, h, c, n, a, h_{\mathrm{A}}, l, m_{\mathrm{T}}, p$ of the voltage-gated ion channels operate according to the first-order kinetic equation

$\frac{d x}{d t}=-\left(\alpha_{x}+\beta_{x}\right) x+\alpha_{x}$, where $x$ is a gating variable and indexes the appropriate rate constant $\alpha_{x}$ and $\beta_{x}$. The inactivation gating variable, $h_{\mathrm{T}}$, for the $I_{\mathrm{T}}$ current was modeled as having two closed states (Wang et al. 1991). The rate of change of $h_{\mathrm{T}}$ had the second-order dynamics,

$\dot{h}_{\mathrm{T}}=\alpha_{h_{\mathrm{T}}}\left(1-h_{\mathrm{T}}-d\right)-\beta_{h_{\mathrm{T}}} h_{\mathrm{T}}$,

Table 2 Simulation parameters

\begin{tabular}{ll}
\hline Temperature & $T=32{ }^{\circ} \mathrm{C}$ \\
Membrane capacitance & $C_{m}=1 \mu \mathrm{F} / \mathrm{cm}^{2}$ \\
Potassium reversal potential & $V_{\mathrm{K}}=-70 \mathrm{mV}$ \\
Leak reversal potential & $V_{\mathrm{L}}=-60 \mathrm{mV}$ \\
Hyperpolarization-activated & $V_{\mathrm{h}}=0 \mathrm{mV}$ \\
reversal potential & \\
LVA calcium reversal & $V_{\mathrm{T}}=120 \mathrm{mV}$ \\
potential & \\
Sodium reversal potential & $V_{\mathrm{Na}}=35 \mathrm{mV}$ \\
Calcium reversal & $V_{\mathrm{Ca}} \approx 120 \mathrm{mV}$ at rest; \\
potential & is variable, see $(2)$ \\
Calcium dissociation & {$\left[\mathrm{Ca}{ }^{2+}\right]_{\mathrm{diss}}=10^{-6} \mathrm{M}$} \\
constant & \\
Extracellular calcium ion & {$\left[\mathrm{Ca}^{2+}\right]_{\mathrm{e}}=1.8 \mathrm{mM}$} \\
concentration & \\
Gas constant & $R=8.314 \mathrm{~J} /(\mathrm{M} \cdot \mathrm{K})$ \\
Faraday constant & $F=9.684 \cdot 10^{4} \mathrm{C} / \mathrm{M}$ \\
\hline
\end{tabular}


where $d$ satisfies

$\dot{d}=\beta_{d}\left(1-h_{\mathrm{T}}-d\right)-\alpha_{d} d$.

The expressions for the voltage-dependent rate constants are given in Table 3.

\section{Ion channel distributions}

The different concentrations of ion channels that were used in different compartments of each RGC are given in Table 4. $\bar{g}_{\mathrm{NaP}}, \bar{g}_{\mathrm{T}}$, and $\bar{g}_{\mathrm{h}}$ were allowed to vary from $\left[10^{-15}, 10^{-1}\right]$ $\mathrm{S} / \mathrm{cm}^{2} \cdot \bar{g}_{\mathrm{h}}$ varied with the same concentration in all regions. The leak current was increased due to the three additional inward currents in comparison to Sheasby and Fohlmeister model as described earlier.

Previous RGCs models (Fohlmeister and Miller 1997; Sheasby and Fohlmeister 1999) have found that in order to reproduce experimentally observed phenomena, it was necessary to increase the sodium channel density in the initial axonal region proximal to the soma. This is supported by recent evidence showing the existence of a low threshold region consisting of a dense band of voltage-gated sodium channels in the initial portion of the RGC axon (Fried et al. 2009; Jeng et al. 2011). This band is located $38.8 \pm 10 \mu \mathrm{m}$ from the soma, with a mean length of $36.8 \pm 5.6 \mu \mathrm{m}$. The exact concentration of sodium in the SOCB in RGCs is unclear.

We modeled the SOCB region with dimensions described in Section 2.1 and with a $\bar{g}_{\mathrm{Na}}$ and $\bar{g}_{\mathrm{NaP}} \mathrm{SOCB}$ to soma ratio, $R_{\mathrm{SOCB}}$,soma, of five. This is consistent with (Jeng et al. 2011) who modeled the SOCB having an increased $\bar{g}_{\mathrm{Na}}$ ratio of 5-50 times the soma concentration. Using this, we found that a distal axon $\bar{g}_{\mathrm{NaP}} 20$ times smaller than the soma $\bar{g}_{\mathrm{NaP}}$ was necessary in order to ensure orthodromic propagation of action potentials and prevent spontaneous activity being generated in the distal axon when there was no spontaneous activity in the soma.

\section{Adjusting leak conductance}

In comparison to the Sheasby and Fohlmeister (1999) model, an increased leak conductance was necessary in our model due to three additional inward currents, $I_{\mathrm{NaP}}, I_{\mathrm{h}}$ and $I_{\mathrm{T}}$, that were not present in the Sheasby and Fohlmeister model. The modification was required to compensate for the additional ion channels without modifying the conductances of other channels. When the maximal leak conductance, $\bar{g}_{\mathrm{L}}$, was initially set uniformly throughout the cell to $8 \times 10^{-6}$ $\mathrm{S} / \mathrm{cm}^{2}$, similar to previous models (Sheasby and Fohlmeister 1999), high frequency spontaneous activity was produced even with low levels of $\bar{g}_{\mathrm{NaP}}$ and $\bar{g}_{\mathrm{T}}$, and also action potentials were evoked during a hyperpolarizing current injection. This value of $\bar{g}_{\mathrm{L}}$ also resulted in the resting potential being 10-30 $\mathrm{mV}$ lower than experimentally recorded (Margolis and Detwiler 2007). In addition, using the value of $\bar{g}_{\mathrm{L}}$ used by Sheasby and Fohlmeister (1999) resulted in the membrane potential during a hyperpolarizing current injection falling more than $100 \mathrm{mV}$ below the resting potential. This is $3-4$ times lower than the potential reached in

Table 3 Rate constants for voltage-gated ion channels ( $\mathrm{V}$ is measured in $\mathrm{mV}$ )

\begin{tabular}{|c|c|c|}
\hline $\mathrm{Na}^{+}$channel & $\alpha_{m}=\frac{-0.6(V+30)}{\exp (-0.1(V+30))-1}$ & $\beta_{m}=20 \exp \left(\frac{-(V+55)}{18}\right)$ \\
\hline & $\alpha_{h}=0.4 \exp \left(\frac{-(V+50)}{20}\right)$ & $\beta_{h}=\frac{6}{1+\exp (-0.1(V+20))}$ \\
\hline $\mathrm{Ca}^{2+}$ channel & $\alpha_{c}=\frac{-0.3(V+13)}{\exp (-0.1(V+13))-1}$ & $\beta_{c}=10 \exp \left(\frac{-(V+38)}{18}\right)$ \\
\hline $\mathrm{K}^{+}$channel & $\alpha_{n}=\frac{-0.02(V+40)}{\exp (-0.1(V+40))-1}$ & $\beta_{n}=0.4 \exp \left(\frac{-(V+50)}{80}\right)$ \\
\hline A channel & $\alpha_{a}=\frac{-0.006(V+90)}{\exp (-0.1(V+90))-1}$ & $\beta_{a}=0.1 \exp \left(\frac{-(V+30)}{10}\right)$ \\
\hline & $\alpha_{h_{\mathrm{A}}}=0.04 \exp \left(\frac{-(V+70)}{20}\right)$ & $\beta_{h_{\mathrm{A}}}=\frac{0.6}{1+\exp (-0.1(V+40))}$ \\
\hline h channel & $\alpha_{l}=\exp (0.08316(V+75))$ & $\beta_{l}=\exp (0.033264(V+75))$ \\
\hline T channel & $\alpha_{m_{\mathrm{T}}}=\left(1.7+\exp \left(\frac{-(V+28.8)}{13.5}\right)\right)^{-1}$ & $\beta_{m_{\mathrm{T}}}=\frac{1+\exp (-(V+63) 7.8)}{1.7+\exp \left(\frac{-(V+28.8)}{13.5}\right)}$ \\
\hline & $\alpha_{h_{\mathrm{T}}}=\exp \left(\frac{-(V+160.3)}{17.8}\right)$ & $\beta_{h_{T}}=\alpha_{h_{T}}\left[0.25+\exp \left(\frac{V+83.5}{6.3}\right)\right]^{0.5}-0.5 \alpha_{h_{T}}$ \\
\hline & $\alpha_{d}=\frac{1+\exp \left(\frac{V+37.4}{30}\right)}{240\left[0.5+\left(0.25+\exp \left(\frac{V+83.5}{6.3}\right)\right)^{0.5}\right]}$ & $\beta_{d}=\alpha_{d}\left[0.25+\exp \left(\frac{V+83.5}{6.3}\right)\right]^{0.5}$ \\
\hline \multicolumn{3}{|l|}{$\mathrm{NaP}$ channel } \\
\hline$[V<-40]$ & $\alpha_{p}=\frac{0.025+0.14 \exp \left(\frac{V+40}{10}\right)}{1+\exp \left(\frac{-(V+48)}{10}\right)}$ & $\beta_{p}=\frac{1-\left(1+\exp \left(\frac{-(V+48)}{10}\right)\right)^{-1}}{0.025+0.14 \exp \left(\frac{V+40}{10}\right)}$ \\
\hline$[V \geq-40]$ & $\alpha_{p}=\frac{0.02+0.145 \exp \left(\frac{-(V+40)}{10}\right)}{1+\exp \left(\frac{-(V+48)}{10}\right)}$ & $\beta_{p}=\frac{1-\left(1+\exp \left(\frac{-(V+48)}{10}\right)\right)^{-1}}{0.02+0.145 \exp \left(\frac{-(V+40)}{10}\right)}$ \\
\hline
\end{tabular}


Table 4 Distribution of ionic channels in cells compartments. Bold conductances were constant across all simulations while conductances below were allowed to vary. Dash indicates the absence of such conductance in the compartment. $\bar{g}_{\mathrm{L}_{0}}=8 \times 10^{-6} \mathrm{~S} / \mathrm{cm}^{2}$ represents the original leak value taken from Fohlmeister and Miller (1997). All conductances are in units of S/cm²

\begin{tabular}{|c|c|c|c|c|c|c|}
\hline & Soma & Dendrites & Initial segment & Narrow region & SOCB & Axon \\
\hline $\bar{g}_{\mathrm{Na}}$ & 0.08 & 0.025 & 0.15 & 0.2 & $5 \times 0.08$ & 0.07 \\
\hline $\bar{g}_{\mathrm{Ca}}$ & 0.0015 & 0.002 & 0.0015 & - & - & - \\
\hline $\bar{g}_{\mathrm{K}}$ & 0.018 & 0.012 & 0.018 & 0.018 & - & 0.018 \\
\hline $\bar{g}_{\mathrm{K}, \mathrm{A}}$ & 0.054 & 0.036 & 0.054 & - & - & - \\
\hline $\bar{g}_{\mathrm{K}(\mathrm{Ca})}$ & 0.000065 & 0.000001 & 0.000065 & 0.000065 & - & 0.07 \\
\hline $\bar{g}_{\mathrm{L}}$ & $15 \times \overline{\mathbf{g}}_{\mathrm{L}_{0}}$ & $15 \times \overline{\mathbf{g}}_{\mathrm{L}_{\mathbf{0}}}$ & $15 \times \overline{\mathbf{g}}_{\mathrm{L}_{0}}$ & $15 \times \overline{\mathbf{g}}_{\mathrm{L}_{0}}$ & $15 \times \overline{\mathbf{g}}_{\mathbf{L}_{0}}$ & $25 \times \overline{\mathbf{g}}_{\mathrm{L}_{0}}$ \\
\hline $\bar{g}_{\mathrm{h}}$ & $\bar{g}_{\mathrm{h}}$ & $\bar{g}_{\mathrm{h}}$ & $\bar{g}_{\mathrm{h}}$ & $\bar{g}_{\mathrm{h}}$ & - & $\bar{g}_{\mathrm{h}}$ \\
\hline $\bar{g}_{\mathrm{NaP}}$ & $\bar{g}_{\mathrm{NaP}}$ & $\bar{g}_{\mathrm{NaP}}$ & $0.05 \times \bar{g}_{\mathrm{NaP}}$ & $0.05 \times \bar{g}_{\mathrm{NaP}}$ & $5 \times \bar{g}_{\mathrm{NaP}}$ & $0.05 \times \bar{g}_{\mathrm{NaP}}$ \\
\hline $\bar{g}_{\mathrm{T}}$ & $\bar{g}_{\mathrm{T}}$ & $5 \times \bar{g}_{\mathrm{T}}$ & $\bar{g}_{\mathrm{T}}$ & $\bar{g}_{\mathrm{T}}$ & $\bar{g}_{\mathrm{T}}$ & $\bar{g}_{\mathrm{T}}$ \\
\hline
\end{tabular}

plots shown in Margolis and Detwiler (2007), which show that the minimum membrane potential reached during a hyperpolarizing current injection was around $30 \mathrm{mV}$ below the resting potential. In order to find an appropriate leak conductance, we investigated the effect of the leak conductance on the cell's input resistance and membrane potential during a hyperpolarizing current injection.

\subsection{Model tuning}

A subset of experimental data from Margolis and Detwiler (2007) was used to evaluate the model parameters $\bar{g}_{\mathrm{NaP}}, \bar{g}_{\mathrm{T}}$, and $\bar{g}_{\mathrm{h}}$. The following data were used for model tuning:

- The value of the mean resting potential for ON cells and the mean resting potential for OFF cells.

- The frequency of the spontaneous activity in OFF sustained (OFF S) and OFF transient (OFF T) cells and the absence of spontaneous activity in ON cells.

- The absence of action potentials during a hyperpolarizing step of $-0.2 \mathrm{nA}$ in both $\mathrm{ON}$ and OFF cells.

- Presence (in OFF cells) or absence (in ON cells) of high frequency burst firing at the termination of a hyperpolarizing step of $-0.2 \mathrm{nA}$.

A comparison of simulation parameter constraints and experimental data is given in Table 5. The resting potential for spontaneously spiking cells was calculated as by Margolis and Detwiler (2007) by removing spikes $2 \mathrm{~ms}$ after reaching a $10 \mathrm{~V} / \mathrm{s}$ threshold and calculating an average over at least $1 \mathrm{~s}$. To calculate the cell's spiking frequency, only action potentials that overshot $0 \mathrm{mV}$ were counted; we call this constraint $\mathrm{C} 0$. The timing of a spike was calculated by recording the time the soma potential exceeded a threshold of $0 \mathrm{mV}$. This timing information was then used to calculate a cell's spiking frequency. Burst frequency was calculated over $200 \mathrm{~ms}$ after termination of the hyperpolarizing current step.
The constraints labeled $\mathrm{C} 1 \mathrm{ON}, \mathrm{C} 1 \mathrm{OFF}$, and $\mathrm{C} 2 \mathrm{OFF}$ are less stringent than the narrow ranges observed in the experimental data allowing the exploration of a larger range of RGCs morphologies. C4 ON further constrained the parameter space by requiring absence of burst firing at the termination of a negative current step for ON cells. In $\mathrm{C} 4$ OFF, the spiking rate during rebound excitation was calculated based on a plot of a sample cell from Margolis and Detwiler (2007) and, therefore, should be taken as indicative only. Frequency has been calculated over $200 \mathrm{~ms}$ after the termination of a hyperpolarizing step.

A search of the parameter space for $\bar{g}_{\mathrm{NaP}}, \bar{g}_{\mathrm{T}}$, and $\bar{g}_{\mathrm{h}}$ was undertaken using variable iteration steps. The parameter space explored was in the range $\bar{g}_{\mathrm{NaP}}, \bar{g}_{\mathrm{T}}, \bar{g}_{\mathrm{h}} \in\left[10^{-15}\right.$, 1] $\mathrm{S} / \mathrm{cm}^{2}$. Initially, logarithmic steps of $10 \mathrm{~S} / \mathrm{cm}^{2}$ were used to explore the parameter space. In order to obtain higher resolution of the $\mathrm{ON}$ and OFF sets, smaller regions were explored where $\bar{g}_{\mathrm{h}}$ varied with logarithmic steps of 10 , and $\bar{g}_{\mathrm{NaP}}$ and $\bar{g}_{\mathrm{T}}$ varied with linear steps. A large parameter space was explored since we expected to find multiple conductance combinations satisfying the constraints listed above. Points satisfying the constraints listed above were recorded and used to determine the conductance limits in $\bar{g}_{\mathrm{NaP}}, \bar{g}_{\mathrm{T}}, \bar{g}_{\mathrm{h}}$ producing $\alpha$-RGC-like behavior. Access to the high performance computational facilities at the Victorian Life Science Computation Initiative (VLSCI) allowed exploration of a large number of morphologies. Parallel simulations using 50 processors were employed to obtain a total of 75,000 CPU hours worth of simulated data.

\subsection{Model validation}

The ability of the model to generalize was tested by comparing the model outputs to data (Mitra and Miller 2007; Margolis and Detwiler 2007) that were not used to constrain the model. Validation criteria below refer only to OFF RGCs 
Table 5 Comparison of simulation parameter constraints and experimental data

\begin{tabular}{|c|c|c|c|}
\hline Constraint & ON RGCs & Model Constraints & Experimental data \\
\hline $\mathrm{C} 0$ & & Spikes overshoot $0 \mathrm{mV}$ & \\
\hline $\mathrm{C} 1 \mathrm{ON}$ & resting potential & {$[-62,-70] \mathrm{mV}$} & $-65.5 \pm 1.3 \mathrm{mV}$ \\
\hline $\mathrm{C} 2 \mathrm{ON}$ & Spontaneous Frequency & $0 \mathrm{~Hz}$ & $0 \mathrm{~Hz}$ \\
\hline $\mathrm{C} 3 \mathrm{ON}$ & $\begin{array}{l}\text { Spike rate during } 500 \mathrm{~ms} \\
\text { stimulus of }-0.2 \mathrm{nA}\end{array}$ & $0 \mathrm{~Hz}$ & $0 \mathrm{~Hz}$ \\
\hline \multirow[t]{2}{*}{$\mathrm{C} 4 \mathrm{ON}$} & $\begin{array}{l}\text { Burst rate at the termination } \\
\text { of } 500 \mathrm{~ms} \text { stimulus of }-0.2 \mathrm{nA}\end{array}$ & $0 \mathrm{~Hz}$ & $0 \mathrm{~Hz}$ \\
\hline & OFF RGCs & Model Constraints & Experimental data \\
\hline $\mathrm{C} 0$ & & Spikes overshoot $0 \mathrm{mV}$ & \\
\hline $\mathrm{C} 1 \mathrm{OFF}$ & resting potential & {$[-50,-62] \mathrm{mV}$} & $\begin{array}{l}-54.6 \pm 1.0 \mathrm{mV}(\text { OFF T) } \\
-55.1 \pm 1.1 \mathrm{mV}(\text { OFF S })\end{array}$ \\
\hline $\mathrm{C} 2 \mathrm{OFF}$ & Spontaneous Frequency & $\begin{array}{l}{[15,23] \mathrm{Hz}(\text { OFF T) }} \\
{[40,48] \mathrm{Hz}(\mathrm{OFF} \mathrm{S})}\end{array}$ & $\begin{array}{l}20.3 \pm 3.0 \mathrm{~Hz}(\text { OFF } \mathrm{T}) \\
43.3 \pm 3.5 \mathrm{~Hz}(\text { OFF S })\end{array}$ \\
\hline C3 OFF & $\begin{array}{l}\text { Spike rate during } 500 \mathrm{~ms} \\
\text { stimulus of }-0.2 \mathrm{nA}\end{array}$ & $0 \mathrm{~Hz}$ & $0 \mathrm{~Hz}$ \\
\hline $\mathrm{C} 4 \mathrm{OFF}$ & $\begin{array}{l}\text { Burst rate at the termination } \\
\text { of } 500 \mathrm{~ms} \text { stimulus of }-0.2 \mathrm{nA}\end{array}$ & $\begin{array}{l}\text { Rebound excitation } \geq 2 \times \\
\text { spontaneous frequency }\end{array}$ & Rebound excitation $60 \mathrm{~Hz}$ \\
\hline
\end{tabular}

since ON cells do not show these phenomena in experiments. Choosing validation criteria that were not used to constrain the model tested the model's predictive capability.

Comparisons of the validation data (labeled V1-V3) and model outputs were made as follows:

- V1: Subthreshold oscillations in OFF cells. When a hyperpolarizing current is applied, OFF cells should reveal oscillations in the subthreshold regime with a rate of $1-10 \mathrm{~Hz}$, similar to the data of Margolis and Detwiler (2007).

- V2: Disruption of spontaneous activity reveals bursting behavior in OFF cells. With negative current steps of increasing amplitude, OFF cells should exhibit a transition from regular spontaneous activity, to irregular activity, to burst firing, and then to silence, as shown experimentally by Margolis and Detwiler (2007).

- V3: Coefficient of variation of the inter-spike interval in OFF cells. The coefficient of variation $(\mathrm{CV})$ is defined as the standard deviation of the inter-spike interval divided by the mean. It is a common measure of the irregularity of spiking, in which a high value $\mathrm{CV}$ reflects high variability and a low value of $\mathrm{CV}$ reflects high regularity. The $\mathrm{CV}$ of the inter-spike interval (ISI) in OFF cells should increase with increasing level of hyperpolarization (Margolis and Detwiler 2007).

To check for $\mathrm{V} 2$ and $\mathrm{V} 3,10$ cells that met constraints $\mathrm{C} 0$ $\mathrm{C} 4$ were simulated and the $\mathrm{CV}$ was plotted against the membrane potential. To calculate the mean membrane potential, spikes were first removed by calculating the derivative of the membrane potential, and removing $2 \mathrm{~ms}$ of data after a $10 \mathrm{mV} / \mathrm{ms}$ threshold was reached. The membrane potential was calculated as the mean potential after spikes were removed. The $\mathrm{CV}$ was calculated in response to increasing $-20 \mathrm{pA}$ current steps, to a maximum of $-80 \mathrm{pA}$.

\section{Results}

To investigate the effect that cell morphology has on the ability to produce the experimentally recorded phenomena listed in Table 5, we compared the total surface areas of the cells and the dendritic surface areas of the cells that met the constraints with those that did not. Furthermore, we explored the effect of reduction of the soma and dendrite surface area on the intrinsic electrophysiological properties of the cells.

In addition to the distribution of ionic channels listed in Table 4, other distribution were explored where the concentration of $\bar{g}_{\mathrm{NaP}}$ and $\bar{g}_{\mathrm{T}}$ were varied in different parts of the cell. Most model variations were eliminated due to unphysiological behaviors described in Section 3.1 or lack of the model's ability to describe $\alpha$-like behavior.

\subsection{Cell morphology}

To examine how the total surface area of the cells affects the intrinsic electrophysiology, we computed the total surface 
area, $S_{\text {total }}$, and the ratio of the dendritic surface area to the total surface area, $R_{\text {dend,total }}$. We compared these morphological features with cells that could meet model constraints C0-C4 from Table 5, and cells that could not meet the constraints. From a total of 200 simulated cells, 88 cells did not meet constraints $\mathrm{C} 0-\mathrm{C} 4$. One third of these did not meet constraint $\mathrm{C} 0$ because they failed to produce action potentials that reached a spike threshold of $0 \mathrm{mV}$. The remaining two-thirds of cells that did not meet the constraints, could not for a variety of reasons including spiking during hyperpolarizing stimulus (C3 ON and C3 OFF). These cells also tended to be cells with larger $S_{\text {total }}$, larger $R_{\text {dend,total }}$ and a lower input resistance, $R_{\text {in }}$. Table 6 shows a comparison of cells meeting constraints $\mathrm{C} 0-\mathrm{C} 4$, and those not meeting constraints. Figure 3 shows histograms depicting how cells were distributed according to $S_{\text {total }}, R_{\text {dend,total }}$ and $R_{\text {in }}$.

The effect of morphology on electrophysiology was investigated further by systematically reducing the cell's dendritic and soma surface areas, while keeping ion channel densities constant. A subset of mouse cells were simulated with the original morphology, then each dendritic compartment diameter was systematically reduced by $10 \%$ to $50 \%$ in $10 \%$ steps. The same protocol was used to explore the effect of reduction of the soma surface area. The resting potential, the derivative of the membrane potential, and spontaneous and rebound burst frequencies were calculated for each reduction in area.

Responses of an OFF S cell with dendritic and soma surface area reduction are shown in Fig. 4. The phase plot of the membrane potential for this cell is shown in Fig. $4 \mathrm{a}$ and $\mathrm{d}$. The arrows show the direction of the phase plot change with decreasing dendritic and soma diameters. Dendritic and soma surface area reduction had significant effects on the phase plot shape and on the cells' spontaneous and burst frequencies. In particular, the phase plot shows that as the dendritic surface area was decreased, the action potentials increased in maximal amplitude and reached a higher rate of change. This resulted in faster action potentials reaching higher amplitudes. Also, the spontaneous frequency decreased with decreasing dendritic diameter but the burst frequency increased (see Fig.4b,c). The opposite happened when the soma surface area was decreased (see Fig. 4e,f). Note that although the surface area was reduced in simulations, the ionic channel conductance concentrations remained fixed.
The cells were also simulated with a reduction in surface area by reducing each dendritic compartment length from $10 \%$ to $50 \%$ in $10 \%$ steps. The results were similar to the results when the dendrite diameters were decreased.

Cells that did not meet the constraints tended to show single action potentials with small voltage fluctuations in the soma. These fluctuations in the membrane potential generally emerged from cells that had very large $S_{\text {total }}$. Having a larger $S_{\text {total }}$ meant that a larger depolarizing potential was necessary to bring the cell to spiking threshold, thereby requiring more than 1 depolarization emerging from the SOCB to cause an action potential. These cells also needed larger hyperpolarizing current steps in order to silence their spontaneous activity. Morphologically, these cells tended to have uniform dendrites with large diameters. Conversely, cells meeting constraints tended to have a mixture of thick and thin dendrites and tapered off much more significantly than cells not meeting constraints $\mathrm{C} 0-\mathrm{C} 4$. A representative sample of cells meeting the constraints are shown in Fig. 1a-c. Figure 1d-f shows representative cells that did not meet the constraints. Note the differences in the morphology between cells in $(\mathrm{a}-\mathrm{c})$ and cells in $(\mathrm{d}-\mathrm{f})$, in particular the smaller somas and uniform diameter dendrites in $(\mathrm{d}-\mathrm{f})$ compared to $(\mathrm{a}-\mathrm{c})$.

\subsection{Model parameters}

\section{Adjusting leak conductance}

The maximal leak conductance, $\bar{g}_{\mathrm{L}}$, was initially set uniformly throughout the cell to $8 \times 10^{-6} \mathrm{~S} / \mathrm{cm}^{2}$, similar to previous models (Sheasby and Fohlmeister 1999). Increasing $\bar{g}_{\mathrm{L}}$ had the effect of increasing the resting potential, and decreasing $R_{\text {in }}$.

In order to find an appropriate value of the $\bar{g}_{\mathrm{L}}$, cells were simulated with increasing levels of $\bar{g}_{\mathrm{L}} . R_{\text {in }}$ as a function of $\bar{g}_{\mathrm{L}}$ for two cells is given in Fig. 5a. Cells were simulated firing spontaneously for $1000 \mathrm{~ms} ; R_{\text {in }}$ was calculated over the last $500 \mathrm{~ms}$ of the simulations. Input resistance into the dendrites was calculated by taking the average resistance of each dendrite stemming from the soma. Simulations showed that $R_{\text {in }}$ decreased exponentially as $\bar{g}_{\mathrm{L}}$ increased. When $\bar{g}_{\mathrm{L}}$ was set to $8 \times 10^{-6} \mathrm{~S} / \mathrm{cm}^{2}$, the cell's input resistance was positioned at a very high level, much higher than values reported in more recent studies
Table 6 Comparison of cells meeting constraints $\mathrm{C} 0-\mathrm{C} 4$ and those not

\begin{tabular}{|c|c|c|c|c|}
\hline & \multicolumn{2}{|c|}{ Cells meeting constraints } & \multicolumn{2}{|c|}{ Cells not meeting constraints } \\
\hline & Mean & Standard deviation & Mean & Standard deviation \\
\hline$R_{\text {dend,total }}$ & 0.84 & 0.16 & 0.97 & 0.04 \\
\hline$S_{\text {total }}\left(\mu \mathrm{m}^{2}\right)$ & 5230 & 2380 & 14226 & 5494 \\
\hline$R_{\text {in }}(\mathrm{M} \Omega)$ & 172.8 & 88 & 68.7 & 25 \\
\hline
\end{tabular}


Fig. 3 Histograms comparing cells that meet model constraints $\mathrm{C} 0-\mathrm{C} 4$ (red) and cells that do not (white). The overlay is shown in pink. a Ratio of dendritic to total surface area, $R_{\text {dend,total }}$. b Total surface area $\left(\mu \mathrm{m}^{2}\right), S_{\text {total }}$. c Input resistance into the dendrites from the soma, $R_{\text {in }}$. Means and standard deviations given in Table 6

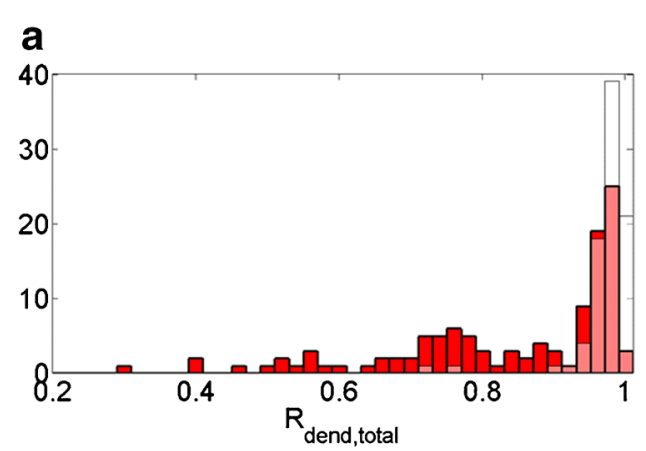

b

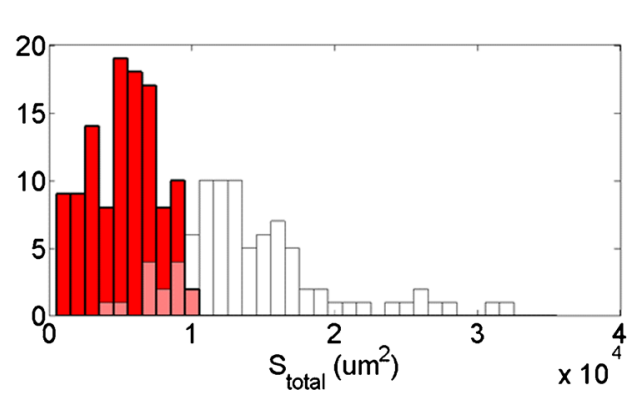

C

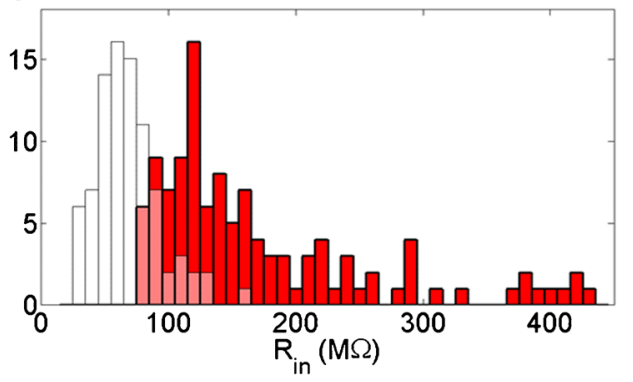

\begin{tabular}{|l|}
$\square$ Cells meeting constraints \\
$\square$ Cells not meeting constraints \\
Overlap
\end{tabular}
(O’Brien et al. 2002; Margolis and Detwiler 2007). By increasing the leak conductance to $1.2 \times 10^{-4} \mathrm{~S} / \mathrm{cm}^{2}(15$ fold increase), the resting potential was increased by 10 $20 \mathrm{mV}$ to around $-60 \mathrm{mV}$. This value of the resting potential was closer to values reported in previous studies (O'Brien et al. 2002; Margolis and Detwiler 2007) for OFF RGCs. This also decreased the $R_{\text {in }}$ to approximately one fifth of its previous value. Further increasing $\bar{g}_{\mathrm{L}}$ did not significantly reduce $R_{\text {in }}$ since the relationship between $R_{\text {in }}$ and $\bar{g}_{\mathrm{L}}$ was exponential. For this reason, an increase of 15 times was used uniformly throughout the cell, except in the distal axon, where it was increased by 25 times. This positioned the resting potential to potentials closer to the level defined in constraints $\mathrm{C} 1 \mathrm{ON}$ and $\mathrm{C} 1 \mathrm{OFF}$.

Increasing $\bar{g}_{\mathrm{L}}$ also had the effect of raising the membrane potential during a $-0.2 \mathrm{nA}$ current step. Figure $5 \mathrm{~b}$ shows how the membrane potential during a $-0.2 \mathrm{nA}$ current step changed as $\bar{g}_{\mathrm{L}}$ was increased. For some cells, the increase in membrane potential over the range shown in Fig. $5 \mathrm{~b}$ was as high as $300 \mathrm{mV}$. For most cells, an increase in $\bar{g}_{\mathrm{L}}$ to $\bar{g}_{\mathrm{L}}=$ $1.2 \times 10^{-4} \mathrm{~S} / \mathrm{cm}^{2}$ positioned the membrane potential during a $-0.2 \mathrm{nA}$ current step at around $-100 \mathrm{mV}$. This is consistent with hyperpolarization potentials shown in various figures by Margolis and Detwiler (2007).

$R_{\text {in }}$ varied substantially from cell to cell. The mean $R_{\text {in }}$ for cells meeting all constraints C0-C4 was $172 \mathrm{M} \Omega$ with a standard deviation of $88 \mathrm{M} \Omega$. This is comparable to values measured by Margolis and Detwiler (2007), where OFF $\mathrm{S}$ cells were recorded between 100 and $140 \mathrm{M} \Omega$, OFF T cells around $60 \mathrm{M} \Omega$, and $\mathrm{ON}$ cells around $55 \mathrm{M} \Omega$. Figure $5 \mathrm{c}$ shows how the cell's input resistance varies in relationship to the total surface area of the cell. The simulation shows a trend of decreasing $R_{\text {in }}$ with increased cell surface area. This is consistent with (O'Brien et al. 2002) who show that alpha cells, which have the largest surface area, have the lowest input resistance, and zeta cells, which have the smallest surface area, have the largest input resistance.

Simulations showed that a higher conductance of $I_{\mathrm{NaP}}$ is necessary in the axonal region corresponding to the SOCB, while a lower $\bar{g}_{\mathrm{NaP}}$ is necessary in the rest of the axon. This ensured that the action potential initiation site was always in the SOCB. A representative example of a recorded action potential in the soma, dendrite, and axon is given in Fig. 6. The time of the action potential peak in the axon segment corresponding to the SOCB is $0.2 \mathrm{~ms}$ earlier than it's time in the soma and $2 \mathrm{~ms}$ earlier than in the distal axon.

An almost linear relationship between spontaneous frequency and $\bar{g}_{\mathrm{NaP}}$ was found. Results showed that values of $\bar{g}_{\mathrm{NaP}}$ above $2 \times 10^{-5} \mathrm{~S} / \mathrm{cm}^{2}$ led to spontaneous activity, as illustrated in Fig. 7. The $\bar{g}_{\mathrm{NaP}}$ activation threshold varied across cells but remained within $1 \times 10^{-5}-3 \times 10^{-5} \mathrm{~S} / \mathrm{cm}^{2}$. Note that an increase in $\bar{g}_{\mathrm{T}}$ also led to an increase in spontaneous activity, generally requiring $\bar{g}_{\mathrm{T}}$ greater than $3 \times 10^{-4}$ $\mathrm{S} / \mathrm{cm}^{2}$ to activate the cell when $\bar{g}_{\mathrm{NaP}}$ was removed; however, the cell output failed to meet constraint $\mathrm{C} 2 \mathrm{ON}$ and $\mathrm{OFF}$, and $\mathrm{C} 3 \mathrm{ON}$ and $\mathrm{OFF}$.

\subsection{Model tuning}

Using the constraints listed in Table 5, we found distinct sets of the parameters $\left(\bar{g}_{\mathrm{NaP}}, \bar{g}_{\mathrm{T}}, \bar{g}_{\mathrm{h}}\right)$ that correspond to ON, OFF T, and OFF $S$ cell populations. The parameter sets for 

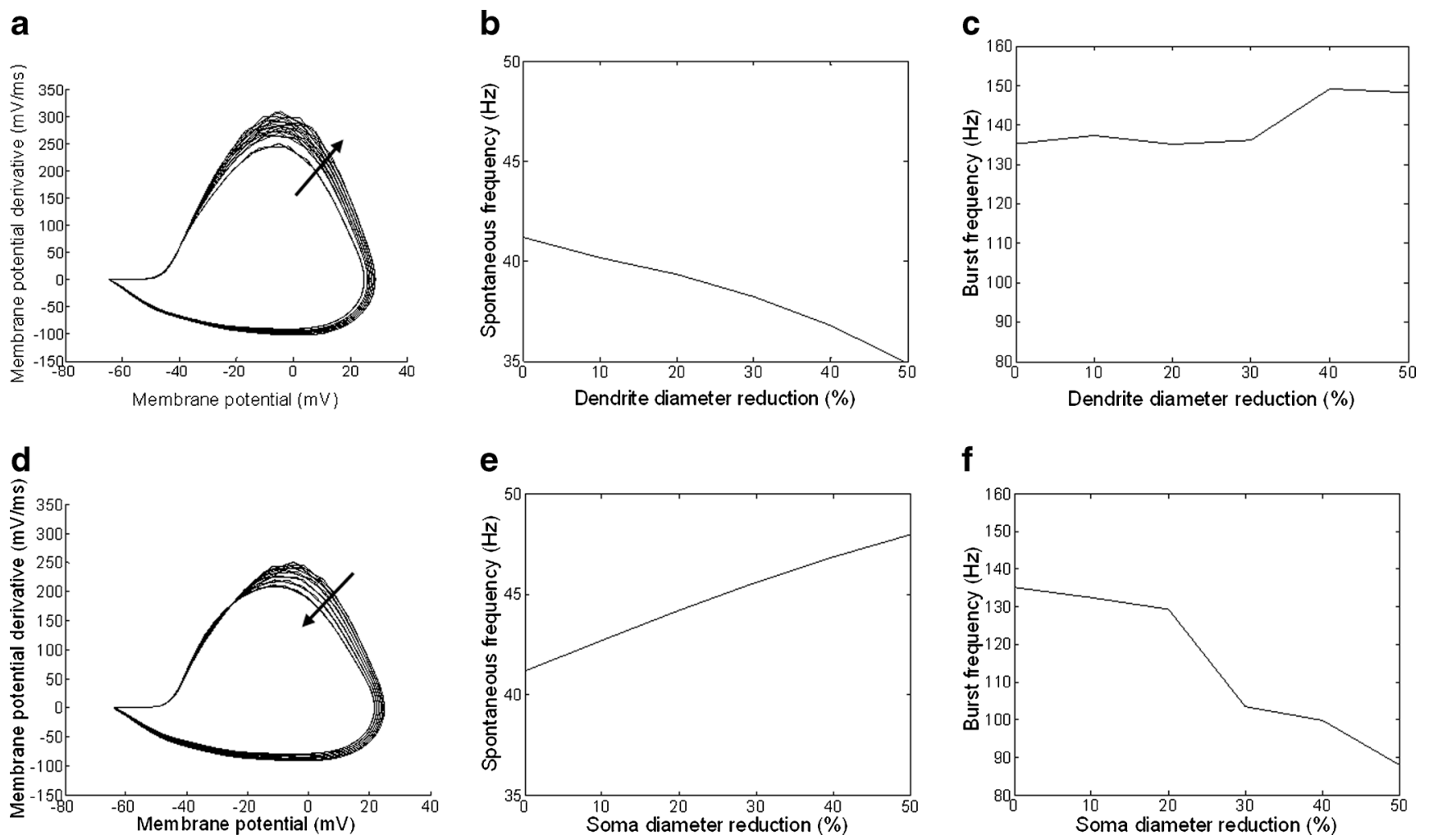

Fig. 4 Effect of reducing the dendritic surface area and of reducing the soma's surface area on a cell's responses. a-c An OFF S cell was simulated under normal conditions and then with the diameter of each dendritic compartment reduced by $10-50 \%$ in steps of $10 \%$. a Phase plot showing that as the surface area is decreased (arrow), the action potentials increase in maximal amplitude and reach a higher rate of change. $\mathbf{b}$ The spike frequency shows a decrease in response to the change in morphology. $\mathbf{c}$ The burst frequency shows an increasing trend in response to the change in morphology. $\mathbf{d}-\mathbf{f}$ An OFF S cell

ON, OFF T and OFF S RGCs are mutually exclusive. Valid sets were defined as connected conductance sets produced by cells meeting constraints outlined in Table 5 . Note that other ionic conductance distributions explored contained cells that could produce points satisfying constraints $\mathrm{C} 0-\mathrm{C} 4$; however, these were eliminated due to the inability to produce valid sets that contained connected conductance sets.

A total of 112 cells (54 of the Salamander cells, and 58 of the Mice cells) produced valid sets. An example of the conductance sets for a cell is illustrated in Fig. 8. The parameter space shown was typical for all cells producing valid sets; however, the linear dependence between $\bar{g}_{\mathrm{T}}$ and $\bar{g}_{\mathrm{NaP}}$ differed slightly for each cell. Other model variations were able to show cells producing sets similar to those shown in Fig. 8, however, the number of cells were much less. Also, the sets produced tended to be much smaller than those presented in Fig. 8, often contained protrusions, and were unable to show the validating constraints like subthreshold oscillations.

In general, the $\mathrm{ON}$ set constraints $\mathrm{C} 0 \mathrm{ON}-\mathrm{C} 4 \mathrm{ON}$ (refer to Table 5) were satisfied for the conductances in the following was simulated under normal conditions and then with the diameter and length of the soma reduced by $10-50 \%$ in steps of $10 \%$. d Phase plot showing that as the surface area is decreased (arrow), the action potentials decrease in maximal amplitude and reach a lower maximal rate of change. This results in slower action potentials reaching lower amplitudes. e The spike frequency shows a steady increase in response to the change in morphology. $\mathbf{f}$ The burst frequency shows a decreasing trend in response to the change in morphology. In simulations $\bar{g}_{\mathrm{NaP}}=$ $3.33 \times 10^{-6} \mathrm{~S} / \mathrm{cm}^{2}, \bar{g}_{\mathrm{T}}=5.36 \times 10^{-4} \mathrm{~S} / \mathrm{cm}^{2}$, and $\bar{g}_{\mathrm{h}}=10^{-9} \mathrm{~S} / \mathrm{cm}^{2}$

ranges: $\bar{g}_{\mathrm{NaP}} \leq 10^{-5}, \bar{g}_{\mathrm{h}} \leq 10^{-5}$, and $\bar{g}_{\mathrm{T}} \leq 10^{-5} \mathrm{~S} / \mathrm{cm}^{2}$. The set did not contain any protrusions or troughs. The set was essentially a rectangular prism indicating that the constraints on $\bar{g}_{\mathrm{NaP}}, \bar{g}_{\mathrm{T}}$, and $\bar{g}_{\mathrm{h}}$ were satisfied independently of one another.

The OFF-T set constraints C0 OFF - C4 OFF were satisfied in the approximate ranges $\bar{g}_{\mathrm{NaP}} \leq 3 \times 10^{-5}, \bar{g}_{\mathrm{T}} \in$ $\left[3 \times 10^{-5}, 4 \times 10^{-4}\right]$, and $\bar{g}_{\mathrm{h}} \leq 10^{-5} \mathrm{~S} / \mathrm{cm}^{2}$.

The OFF-S set constraints C0 OFF - C4 OFF were satisfied in the ranges similar to OFF T: $\bar{g}_{\mathrm{NaP}} \leq 3.5 \times 10^{-5}, \bar{g}_{\mathrm{T}} \in$ $\left[3.5 \times 10^{-5}, 7 \times 10^{-4}\right]$, and $\bar{g}_{\mathrm{h}} \leq 10^{-5} \mathrm{~S} / \mathrm{cm}^{2}$.

The parameter set region was found to be roughly the same for all morphologies of RGCs that satisfied constraints $\mathrm{C} 0-\mathrm{C} 4$. However, the shape of the parameter set region varied slightly between cells within the limits given above.

All sets showed little or no dependence on $\bar{g}_{\mathrm{h}}$. These results and the validation results show that while $I_{\mathrm{h}}$ produces the characteristic sag seen at the onset of a negative current injection, it only has a modulatory role in shaping the cell response. 
Fig. 5 Effect of leak conductance, $\bar{g}_{\mathrm{L}}$, and total surface area, $S_{\text {total }}$, on the input resistance, and on the membrane potential during a $-0.2 \mathrm{nA}$ current step. a Input resistance, $R_{\text {in }}$ as a function of $\bar{g}_{\mathrm{L}} \cdot \mathbf{b}$ Membrane potential during a $-0.2 \mathrm{nA}$ current step as a function of $\bar{g}_{\mathrm{L}}$. In simulations for $\mathbf{a}$ and $\mathbf{b}$, dashed: cell from the Salamander set; Solid: cell from the mouse set. In simulations, $\bar{g}_{\mathrm{NaP}}=1 \times 10^{-5}$ $\mathrm{S} / \mathrm{cm}^{2}, \bar{g}_{\mathrm{T}}=3 \times 10^{-4} \mathrm{~S} / \mathrm{cm}^{2}$ and $=1 \times 10^{-9} \mathrm{~S} / \mathrm{cm}^{2}$. c Input resistance, $R_{\text {in }}$ as a function of total surface area, $S_{\text {total }}$. Each individual dot represents a cell. Red: curve fit using a power fit of the form $y=a x^{b}$, where $a=1.17 \times 10^{22}, b=-4.58$. In simulations $\bar{g}_{\mathrm{NaP}}=1 \times 10^{-5}$ $\mathrm{S} / \mathrm{cm}^{2}, \bar{g}_{\mathrm{T}}=3 \times 10^{-4} \mathrm{~S} / \mathrm{cm}^{2}, \bar{g}_{\mathrm{h}}$ $=1 \times 10^{-9} \mathrm{~S} / \mathrm{cm}^{2}$, and $\bar{g}_{\mathrm{L}}=$ $1.2 \times 10^{-4} \mathrm{~S} / \mathrm{cm}^{2}$
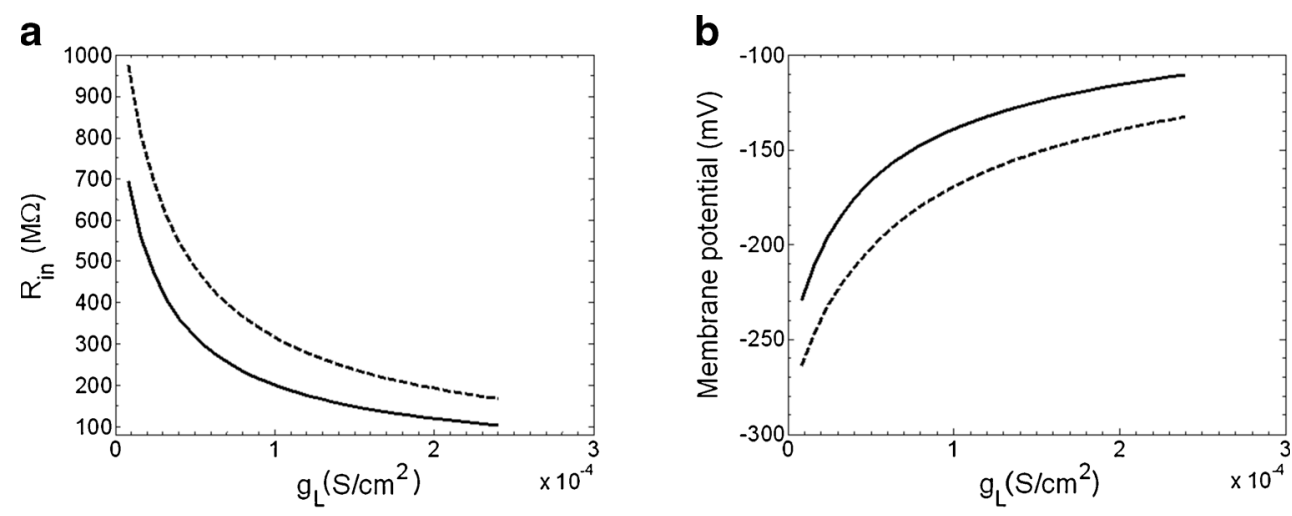

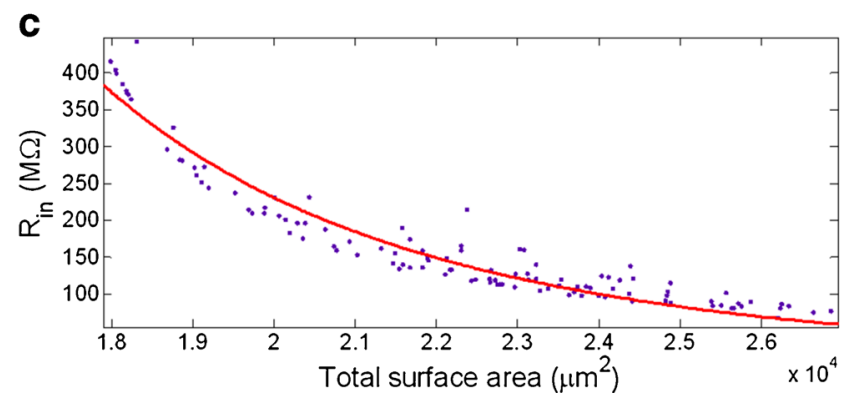

\subsection{Model validation}

To validate the model, outputs were compared to experimental data V1 - V3 that were not used to constrain the model. In order to explore the ability of the cells to produce subthreshold oscillations and burst firing, a sample of 80 cells was chosen. Five conductance points in each set with conductance values denoted by $\mathrm{A}, \mathrm{B}, \mathrm{C}, \mathrm{D}$, and $\mathrm{E}$ in Fig. 9 were chosen to check for the presence of oscillations and burst firing. These points changed slightly from cell to cell according to the conductance set produced for each cell. A total of eight current steps each of $2 \mathrm{~s}$ duration was simulated for a total of $17 \mathrm{~s}$.

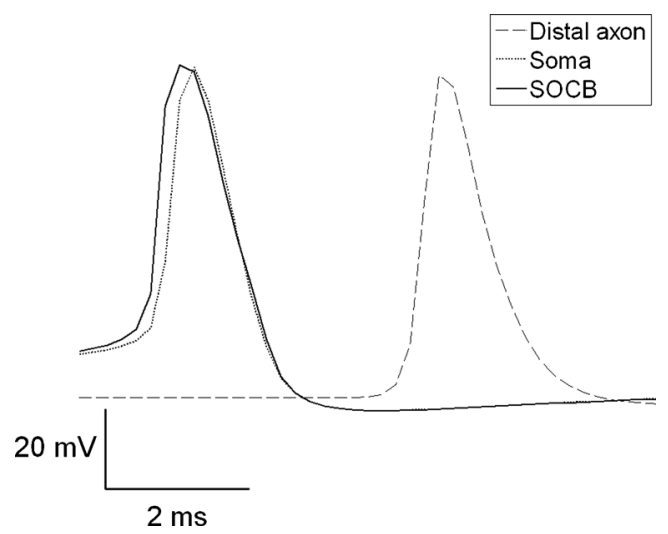

Fig. 6 The action potential initiation site is in the axon's SOCB. Voltage traces are shown for a representative cell. Recordings are made in the soma, distal axon and SOCB. For this simulation $\bar{g}_{\mathrm{NaP}}=1 \times 10^{-5}$ $\mathrm{S} / \mathrm{cm}^{2}, \bar{g}_{\mathrm{T}}=3 \times 10^{-4} \mathrm{~S} / \mathrm{cm}^{2}$ and $\bar{g}_{\mathrm{h}}=1 \times 10^{-9} \mathrm{~S} / \mathrm{cm}^{2}$
Figure 9 gives an example of the cell's response to a hyperpolarizing step current. Shown are voltage traces taken for the five points for a mouse cell. Only points D and E were able to produce sustained oscillations. While this is typical of most of the cells producing oscillations, some cells also produced oscillations at point $C$. This indicates that high levels of $\bar{g}_{\mathrm{T}}$ are necessary in order to produce oscillations. Note that the inserted voltage traces are illustrative, and the time and voltage axis may be different for each trace.

Figure 9 shows that the interplay between $\bar{g}_{\mathrm{NaP}}$ and $\bar{g}_{\mathrm{T}}$ is crucial for generating subthreshold oscillations. $I_{\mathrm{L}}$ also plays an important role in positioning the membrane potential in the activation range of $I_{\mathrm{NaP}}$ and playing a modulatory

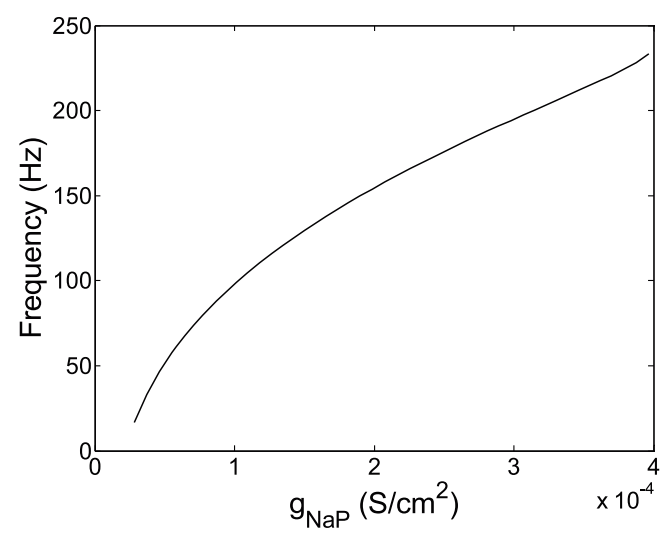

Fig. 7 Spiking frequency as a function of $\bar{g}_{\mathrm{NaP}}$ is plotted for a representative cell, showing a monotonically increasing relationship between $\bar{g}_{\mathrm{NaP}}$ and spontaneous frequency. For this simulation $\bar{g}_{\mathrm{T}}=$ $3 \times 10^{-4} \mathrm{~S} / \mathrm{cm}^{2}$ and $\bar{g}_{\mathrm{h}}=1 \times 10^{-9} \mathrm{~S} / \mathrm{cm}^{2}$ 


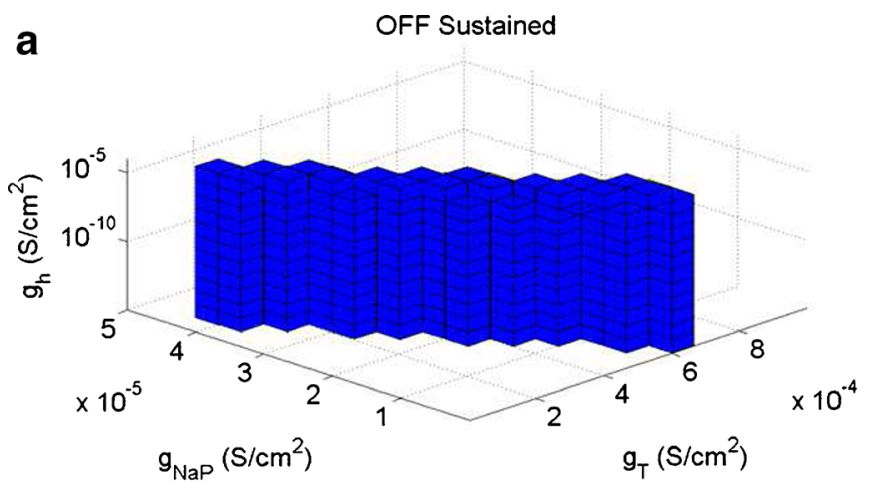

C

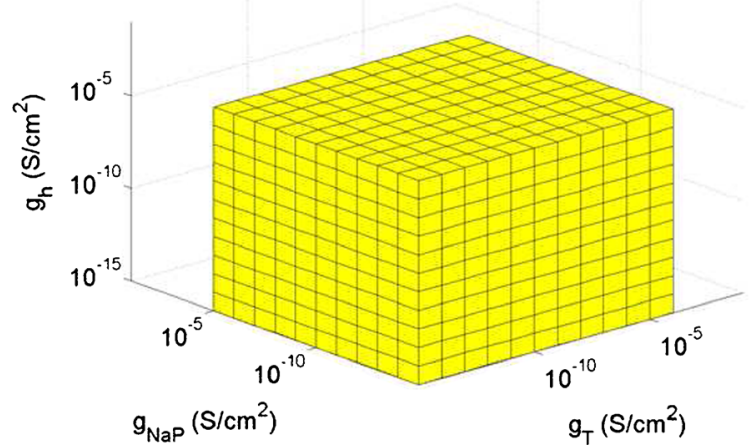

Fig. 8 Typical ON and OFF RGCs parameter sets for conductances $\bar{g}_{\mathrm{h}}, \bar{g}_{\mathrm{T}}$, and $\bar{g}_{\mathrm{NaP}}$. Colored cubes indicate parameter values that satisfy the constraints $\mathrm{C} 0$ - C4. a OFF S RGCs set. b OFF T RGCs set. $\mathbf{c}$ ON RGCs set. d Representative figure to give an indication of how each set fits together within the parameter space. No sets overlap. Logarithmic steps were used to explore the parameter space in $\bar{g}_{\mathrm{h}}$ while linear steps were used for $\bar{g}_{\mathrm{T}}$ and $\bar{g}_{\mathrm{NaP}}$ in OFF RGCs. Logarithmic steps were used in $\mathrm{ON}$ cells. The sets were found under model constraints $\mathrm{C} 0-\mathrm{C} 4 \mathrm{ON}$

role in subthreshold oscillations. With a low amplitude hyperpolarizing current injection, cells are hyperpolarized to approximately $-63 \mathrm{mV}$, close to the reversal potential for $\bar{g}_{\mathrm{L}}$. The presence of $I_{\mathrm{NaP}}$ provides the constant inward current that depolarizes the membrane potential and creates a feedback loop with $\bar{g}_{\mathrm{L}}$. In response, $\bar{g}_{\mathrm{L}}$ oscillates from an inward to outward current. These oscillations are soon damped if $\bar{g}_{\mathrm{T}}$ is only present in small concentrations. With higher concentrations of $\bar{g}_{\mathrm{T}}$, small and rapid membrane depolarization activate large spikes of $I_{\mathrm{T}}$ current. This provides the necessary drive to create fluctuations in the membrane potential and burst of spikes at a higher level of hyperpolarization. Maximal levels of $\bar{g}_{\mathrm{T}}$ resulted in sustained oscillations of anywhere between 0.5 and $10 \mathrm{mV}$ in amplitude.

The presence of subthreshold oscillations was checked in 80 out of the 112 cells that produced valid sets. The presence of subthreshold oscillations varied substantially across different cell morphologies. 37 cells out of 80 cells were able to show these features in at least one of C, D, or F. In all cases, only points $\mathrm{C}$, D, or E in Fig. 9 could satisfy $V 1$ and $V 2$

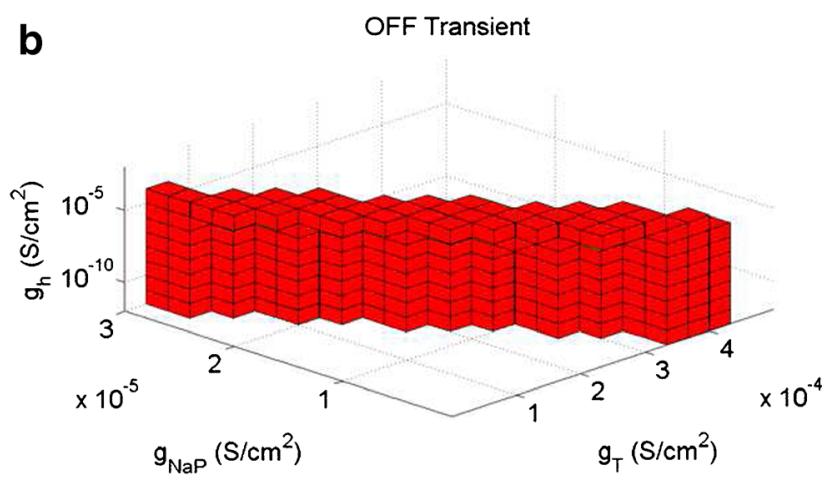

d

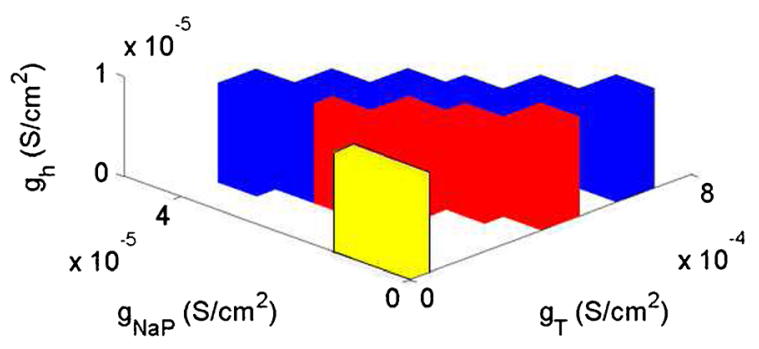

for the ON set and $\mathrm{C} 0$ - C4 OFF for the OFF sets (see Table 5). The cell illustrated here was a mouse cell. Results are typical for all cells producing valid sets. All parameters in the Hodgkin-Huxley scheme were fixed except for $\bar{g}_{\mathrm{h}}, \bar{g}_{\mathrm{T}}$ and $\bar{g}_{\mathrm{NaP}}$. The parameter space $\bar{g}_{\mathrm{h}} \in\left[10^{-15}, 1\right]$ $\mathrm{S} / \mathrm{cm}^{2}, \bar{g}_{\mathrm{T}} \in\left[10^{-15}, 1\right] \mathrm{S} / \mathrm{cm}^{2}, \bar{g}_{\mathrm{NaP}} \in\left[10^{-15}, 1\right] \mathrm{S} / \mathrm{cm}^{2}$ was explored. However, a reduced parameter space is illustrated to emphasize the region producing valid sets

indicating that $\bar{g}_{\mathrm{T}}$ had to be greater than $3 \times 10^{-4} \mathrm{~S} / \mathrm{cm}^{2}$ to show the phenomenon. In all cases, only conductances from the OFF S set could produce sustained oscillations. Conductances from the OFF $\mathrm{T}$ set could only produce damped oscillations.

An example of the proportion of the points in the set satisfying validation constraint $V 1$ for an OFF $S$ cell is given by the red cubes in Fig. 9. The proportion was typical for OFF $\mathrm{S}$ cells that produced subthreshold oscillations. The amplitude of oscillation was $1-5 \mathrm{mV}$, the frequency of oscillation was between 1 and $10 \mathrm{~Hz}$, which corresponds well with experimental results of 2 $8 \mathrm{~Hz}$ from Margolis and Detwiler (2007). Parameter values represented by cubes in red produced sustained oscillations. Some of the parameter values corresponding to yellow cubes close to the red section produced damped oscillations.

Figure 10 shows responses from a mouse cell of two points from the red region in Fig. 9 to a hyperpolarizing current step. Figure 10a shows oscillations with bursting behavior. This is similar to the type of oscillations OFF T 
Fig. 9 The ability of the cells to produce subthreshold oscillations and burst firing for conductance points A, B, C, D, and $\mathrm{E}$ is illustrated. Shown are voltage traces for five points from a mouse cell. Voltage traces for all five points are in response to seven increasing hyperpolarizing current steps, each of $-0.02 \mathrm{nA}$ and each for $2 \mathrm{~s}$ duration. The eighth current step is $-0.2 \mathrm{nA}$ and $0.5 \mathrm{~s}$ duration. Voltage traces for points $\mathrm{D}$ and $\mathrm{E}$ are cropped to highlight the cell's response. For this cell, only conductances in the red region were able to produce sustained oscillations

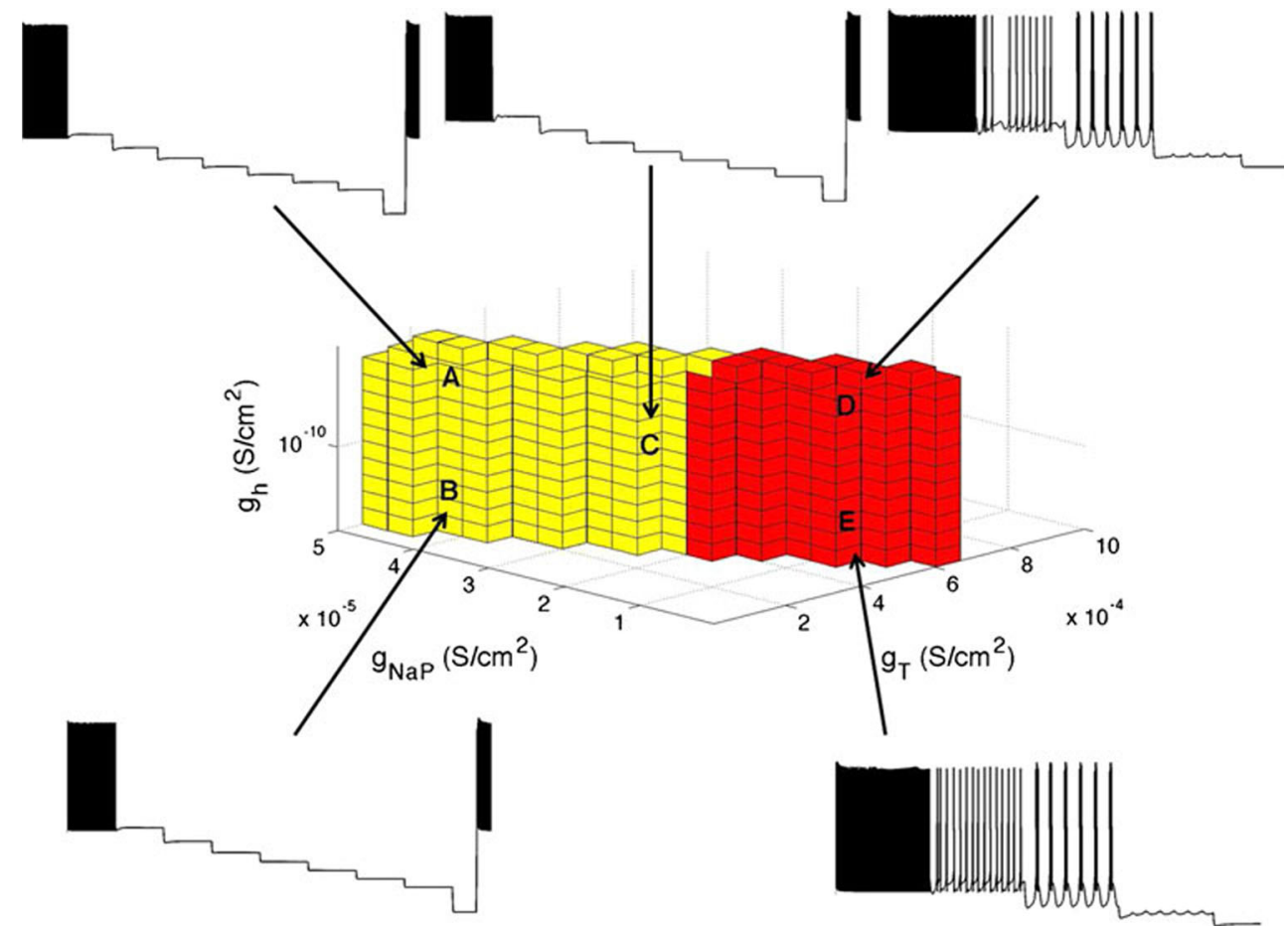

cells produced in our simulations. Figure $10 \mathrm{~b}$ shows subthreshold oscillations for an OFF S cell. Oscillations were observed between 3-5 Hz, which was confirmed by power spectrum analysis (data not shown).

Figure 11 shows a comparison of the experimental results and simulation results for OFF S RGCs. Figure 11 shows that with an increasing level of hyperpolarization, cells transit from regular spiking to spiking at a lower frequency, to irregular spiking, to burst spiking and then to quiescence, satisfying V1-V3. Values of the CV is shown beside each simulated figure. The increasing values show that there is an increase in the spike irregularity.

Figure 12 compares experimental values of the $\mathrm{CV}$ to simulated responses. Figure $12 \mathrm{a}-\mathrm{c}$ are experimental responses for $\mathrm{ON}$, OFF $\mathrm{T}$ and $\mathrm{OFF} \mathrm{S}$ cells respectively. Figure $12 \mathrm{~d}-\mathrm{e}$ are simulated responses for $\mathrm{ON}, \mathrm{OFF} \mathrm{T}$ and OFF $S$ cells respectively. In the simulated ON plot, conductance values corresponding to extreme conductances from the set in Fig. 8c were chosen. All conductance values produced similar results, therefore only the result for one conductance point is shown in Fig. 12d. In this plot, the conductance values are $\bar{g}_{\mathrm{NaP}}=1 \times 10^{-5} \mathrm{~S} / \mathrm{cm}^{2}$, $\bar{g}_{\mathrm{T}}=1 \times 10^{-5} \mathrm{~S} / \mathrm{cm}^{2}$, and $\bar{g}_{\mathrm{h}}=1 \times 10^{-5} \mathrm{~S} / \mathrm{cm}^{2}$. In ON simulations, cells were first depolarized by injecting $50 \mathrm{pA}$. In the simulated $\mathrm{OFF}$ plots, 5 conductance points were taken from the OFF $\mathrm{T}$ and $\mathrm{OFF} \mathrm{S}$ sets similar to the points A-E shown in Fig. 9. Since points $A$ and B produced silent responses after small hyperpolarizing current steps, the results from these points were omitted from Fig. 12e-f. A linear fit was applied to the simulated data for points C-E.

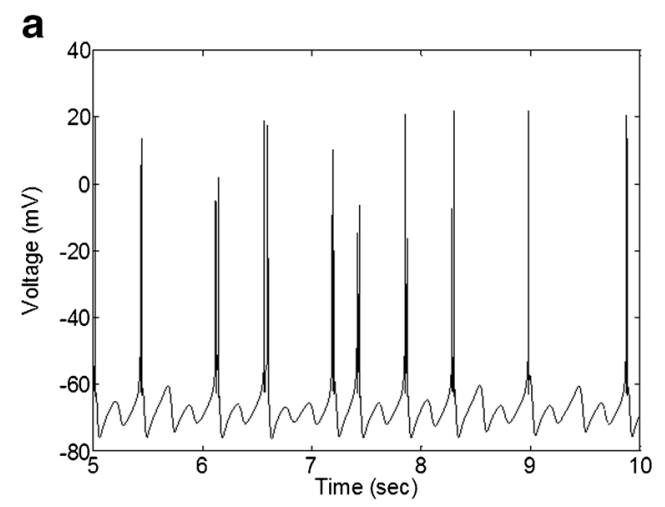

b

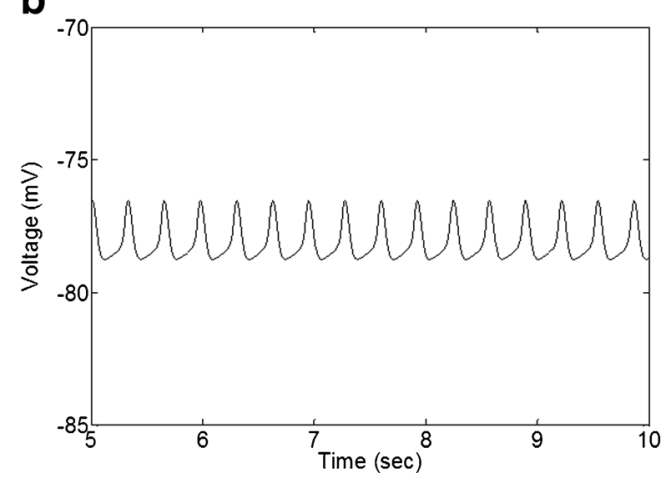

Fig. 10 Responses of two points from the red set in Fig. 9 to a hyperpolarizing current step. Both plots show oscillations between 3 and $5 \mathrm{~Hz} . \mathbf{a} \bar{g}_{\mathrm{NaP}}=6.67 \times 10^{-6} \mathrm{~S} / \mathrm{cm}^{2}, \bar{g}_{\mathrm{T}}=4.69 \times 10^{-4} \mathrm{~S} / \mathrm{cm}^{2}, \bar{g}_{\mathrm{h}}=$ $10^{-5} \mathrm{~S} / \mathrm{cm}^{2}$, and $\mathrm{I}_{\text {stim }}=-0.07 \mathrm{nA} . \mathbf{b} \bar{g}_{\mathrm{NaP}}=6.67 \times 10^{-6} \mathrm{~S} / \mathrm{cm}^{2}$, $\bar{g}_{\mathrm{T}}=5.36 \times 10^{-4} \mathrm{~S} / \mathrm{cm}^{2}, \bar{g}_{\mathrm{h}}=10^{-14} \mathrm{~S} / \mathrm{cm}^{2}$, and $\mathrm{I}_{\text {stim }}=-0.06 \mathrm{nA}$ 
a

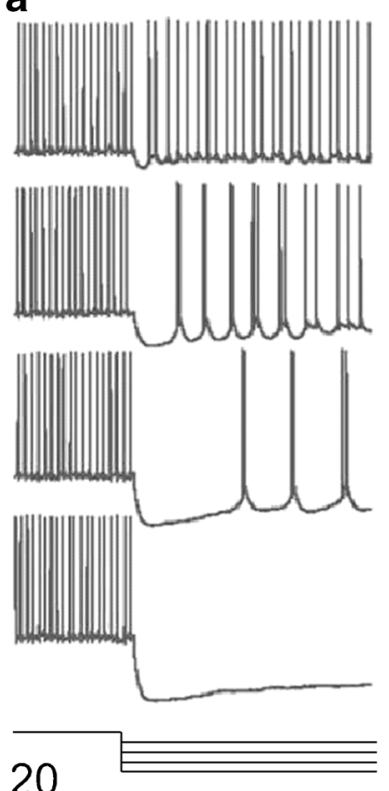

20

$0.2 \mathrm{~s}$ Experiment b
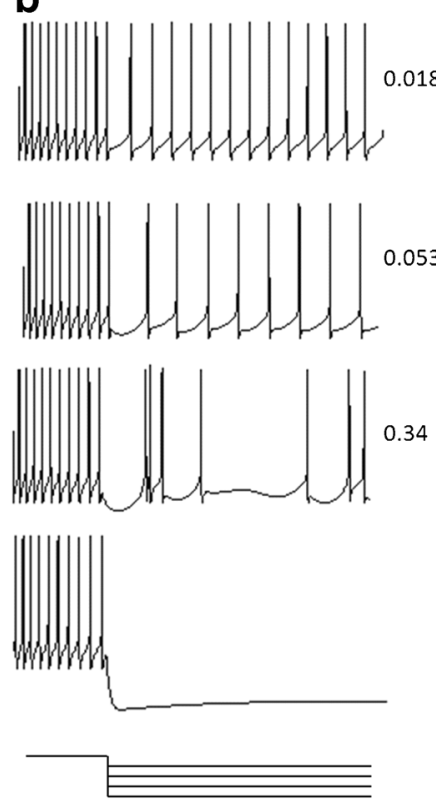

Salamander cell
C
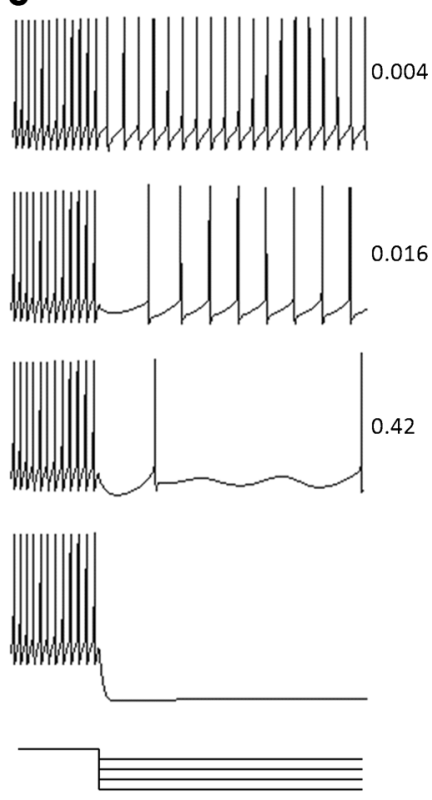

Mouse cell
Fig. 11 Comparison of the experimental results and simulated results for OFF S RGCs to increasing levels of hyperpolarizing current injection. Experimental and simulated responses show transitions from regular spiking to quiescence (V2) and an increase in the CV (V3). Numbers next to simulated responses show the CV. CV was calculated over $10 \mathrm{~s}$ of simulated data. The time and voltage scale applies to all plots. Current steps are superimposed and shown below voltage recordings. a Experimental data from Margolis and Detwiler (2007). b Simulation of a salamander cell. In these simulations, $\bar{g}_{\mathrm{NaP}}=$ $3.33 \times 10^{-6} \mathrm{~S} / \mathrm{cm}^{2}, \bar{g}_{\mathrm{T}}=5.36 \times 10^{-4} \mathrm{~S} / \mathrm{cm}^{2}$, and $\bar{g}_{\mathrm{h}}=10^{-5} \mathrm{~S} / \mathrm{cm}^{2}$. c Simulation of a mouse cell. In these simulations, $\bar{g}_{\mathrm{NaP}}=2.33 \times 10^{-5}$ $\mathrm{S} / \mathrm{cm}^{2}, \bar{g}_{\mathrm{T}}=2.7 \times 10^{-4} \mathrm{~S} / \mathrm{cm}^{2}$, and $\bar{g}_{\mathrm{h}}=10^{-11} \mathrm{~S} / \mathrm{cm}^{2}$. Current steps for both simulation are: $-0.02,-0.04,-0.06,-0.14 \mathrm{nA}$. Experimental figures adapted from Margolis and Detwiler (2007) with permission
Note that the linear fit for the points D and $\mathrm{E}$ in the OFF T and OFF S sets are almost identical. We found that the slope of the fit is dependent on the conductance values. In particular, the slope of the fit became more negative as $\bar{g}_{\mathrm{T}}$ increased and $\bar{g}_{\mathrm{NaP}}$ decreased, however it had little dependence on $\bar{g}_{\mathrm{h}}$.

Figure 13 shows a comparison of the experimental results and simulation results for ON, OFF T, and OFF S RGCs from the mouse set. It can be seen that different hyperpolarizing current levels are required to generate oscillations in each cell. The level required to silence the output varied from cell to cell. In simulations, ON cells were first depolarized with a $60 \mathrm{pA}$ current injection to elicit action potentials. ON cells showed no bursting at any stage. Bursting at intermediate levels of hyperpolarization in OFF T cells was a far less common feature than in OFF S. This is consistent with reports from Margolis and Detwiler (2007) where only 2 of 10 cells showed weak bursts. OFF $S$ cells showed transitions from regular firing to irregular bursts, subthreshold oscillations and then to quiescence. This pattern in the transition was observed far less in OFF T cells. Our model showed that OFF $\mathrm{T}$ could only produce oscillations between bursts (see OFF T response in Fig. 13), whereas OFF S cells could produce sustained oscillations (see Figs. 9 and 10c). The amplitude of oscillations that were produced varied with conductance and morphology. In general, the amplitude of oscillations was $2-3 \mathrm{mV}$ peak-to-peak; however, in some cases this reached around $10 \mathrm{mV}$.

We found that $\bar{g}_{\mathrm{T}}$ needed to be greater than $3 \times 10^{-5}$ $\mathrm{S} / \mathrm{cm}^{2}$ in order to generate high frequency bursting in OFF RGCs. Values of $\bar{g}_{\mathrm{T}}$ closer to the maximal level tended to produce a latent period where small oscillations were produced between bursts of action potentials. The duration of this latent period varied across cells but was directly correlated to the amount of $I_{\mathrm{T}}$ current induced by the termination of negative current injection and the inactivation time of this current to a lower amplitude. This phenomenon is not unusual for other cell types such as hippocampal neurons (Ullah and Schiff 2010). Figure 14 shows a soma membrane potential (green trace) and $I_{\mathrm{T}}$ current (black trace) on the same time scale. It can be observed that the latent period is related to the inactivation time of $I_{\mathrm{T}}$ current. In simulations, the latent period can last 20-80 ms.

In addition to the above, the level of hyperpolarization during a current step of $-0.2 \mathrm{nA}$ was recorded for all 


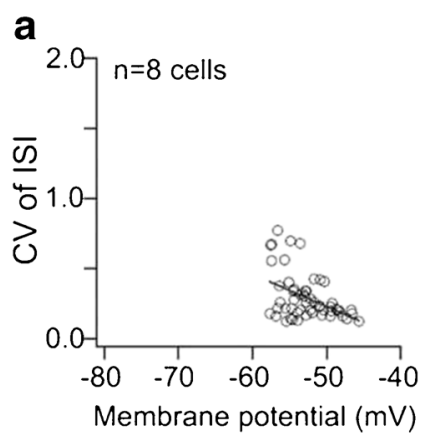

d

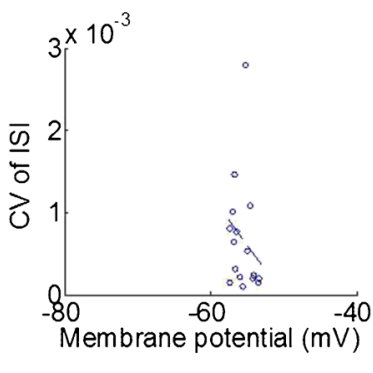

b

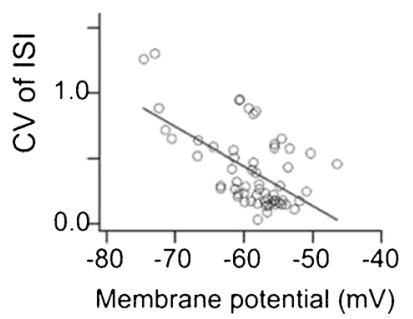

e
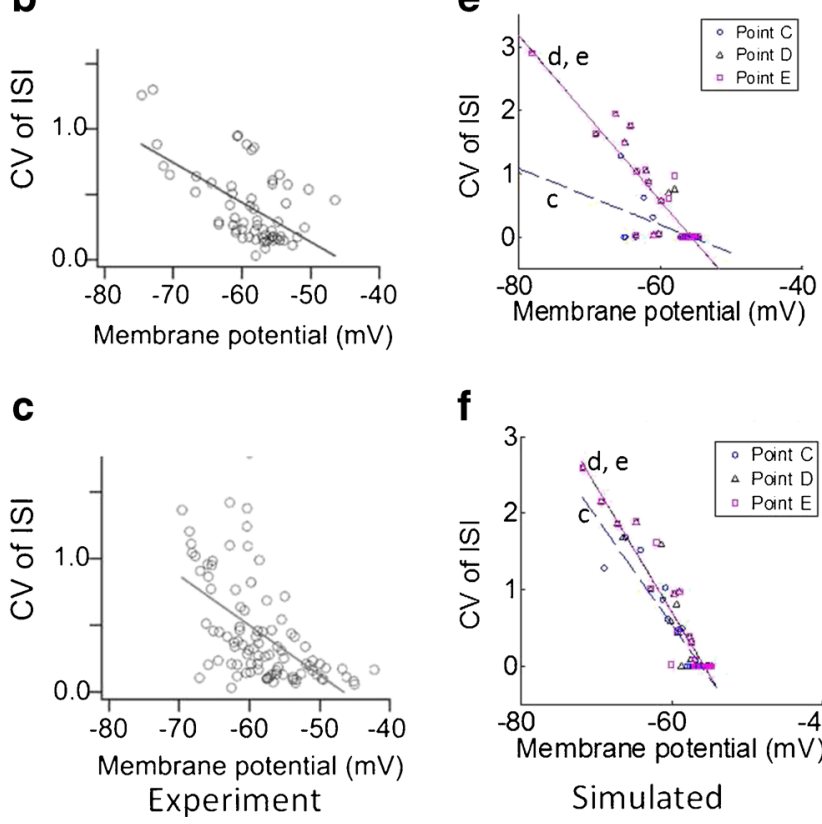

f

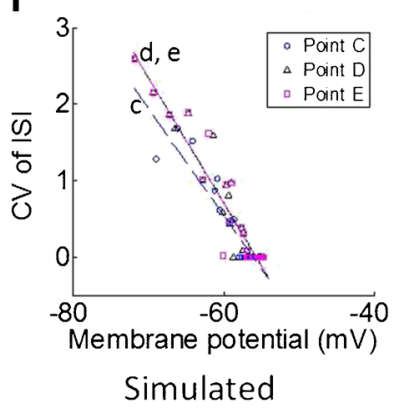

Fig. 12 Comparison of the coefficient of variation of the interspike interval (CV of ISI) against membrane potential. a-c show experimental results from Margolis and Detwiler (2007). d-f show simulated results. a d, b e, and $\mathbf{c} \mathbf{f}$ show results for ON, OFF T and OFF S cells respectively. Simulated results represent 10 cells that met constraints $\mathrm{C} 0-\mathrm{C} 4$. These cells were simulated with increasing negative current steps, to a maximum of $-80 \mathrm{pA}$. Each marker in the OFF plots represent different conductance values for $\bar{g}_{\mathrm{T}}, \bar{g}_{\mathrm{NaP}}$, and $\bar{g}_{\mathrm{h}}$. A linear fit was applied to the data. In OFF plots, a letter indicates which fit it corresponds to. Note that the CV of ISI axis in simulated plots is different to the CV of ISI axis on experimental results. Experimental figures adapted from Margolis and Detwiler (2007) with permission

cells. The value of the membrane potential during hyperpolarization was $20-40 \mathrm{mV}$ below the resting potential, which corresponds well with experimental data (Margolis and Detwiler 2007).

Also, the relative amplitude of the sag during a hyperpolarizing step of $-0.2 \mathrm{nA}$ was recorded for all cells. The amplitude was between 1 and $2 \mathrm{mV}$, which corresponds well with experimental data (O'Brien et al. 2002; Margolis and Detwiler 2007).

\section{Discussion}

In this paper, we present realistic, morphologically correct models of $200 \mathrm{ON}$ and OFF RGCs, and test ionic channel densities in morphological compartments that are necessary to capture experimentally recorded phenomena described by Margolis and Detwiler (2007). In particular, we showed the presence of subthreshold oscillations, burst firing, and spontaneous activity in the absence of synaptic input in OFF RGCs and the absence of such in ON RGCs. Our model predicted that the differences between ON and OFF cells are based on the presence of $\mathrm{LVA} \mathrm{Ca}^{2+}$ current in OFF cells and absence of such in ON cells.

We found distinct sets of the parameters, $\bar{g}_{\mathrm{NaP}}, \bar{g}_{\mathrm{T}}$, and $\bar{g}_{\mathrm{h}}$, that correspond to ON and OFF cell populations. In general, the values in the ranges $\bar{g}_{\mathrm{NaP}} \leq 10^{-5}, \bar{g}_{\mathrm{h}} \leq 10^{-5}$, and $\bar{g}_{\mathrm{T}} \leq 10^{-5} \mathrm{~S} / \mathrm{cm}^{2}$ produced valid parameter sets for ON RGCs. The values in the ranges $\bar{g}_{\mathrm{NaP}} \leq 3 \times 10^{-5}, \bar{g}_{\mathrm{T}}$ $\in\left[3 \times 10^{-5}, 4 \times 10^{-4}\right]$, and $\bar{g}_{\mathrm{h}} \leq \times 10^{-5} \mathrm{~S} / \mathrm{cm}^{2}$ produced valid OFF cell parameter sets. These values were similar to those found in single compartment models described by Kameneva et al. (2011). The present study, however, extends the results of previous modeling studies by explicitly examining the effect of changes to the single compartmental morphological structure of the neurons.

This study shows that not all cell morphologies match the RCG behavior described by Margolis and Detwiler (2007). We found that the cells that were able to reproduce the described phenomena had smaller total surface area, $S_{\text {total }}$, and in general, a smaller ratio of dendritic to total surface area, $R_{\text {dend,total }}$. This illustrates that morphology plays an important role in shaping the cell's response. These results are in agreement with Fohlmeister and Miller (1997), who showed that the cell morphology play a role in firing patterns and the impulse frequency response. However, Fohlmeister and Miller (1997) also claimed that the ion channel distribution plays a secondary role in these functions. However, our results illustrate how the channel density distribution plays an important role in intrinsic electrophysiological properties of RGCs.

Since the NeuroMorpho database does not distinguish the cell subtypes, or whether they are ON or OFF RGCs, it is unclear what morphological cell types were actually able to satisfy the modeling constraints. Determining the subtypes of the 200 cells used in this study requires electrophysiological identification on each cell model. This investigation is left for future work.

The difference in LVA $\mathrm{Ca}^{2+}$ current in ON and OFF RGCs suggests that this current contributes to differences in the way these cell types process visual information. It was proposed that $\mathrm{LVA} \mathrm{Ca}^{2+}$ current initiates rebound excitation in OFF RGCs to generate a precisely timed OFF response at the termination of a light stimulus (Margolis et al. 2010). 


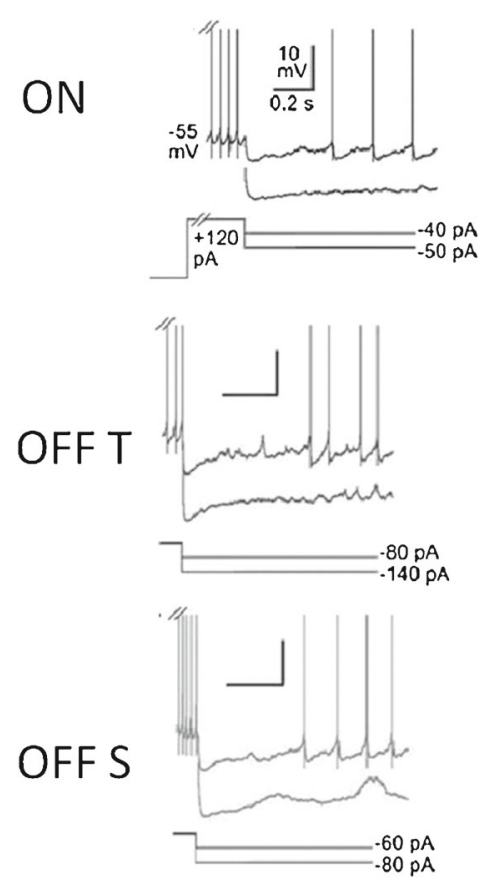

\section{Experiment}
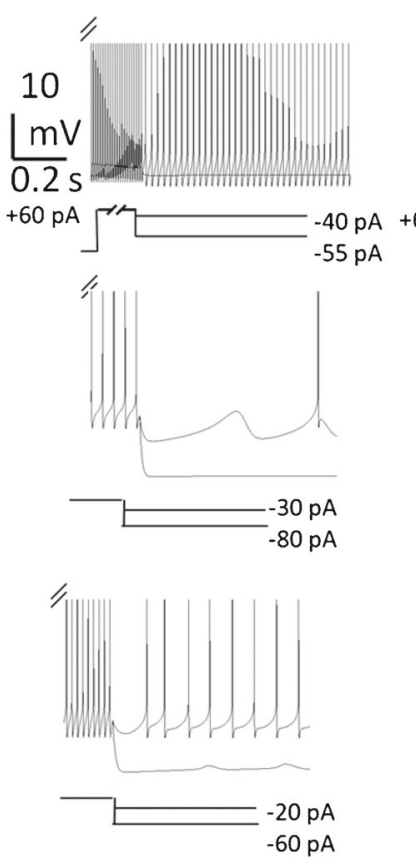

Salamander cell
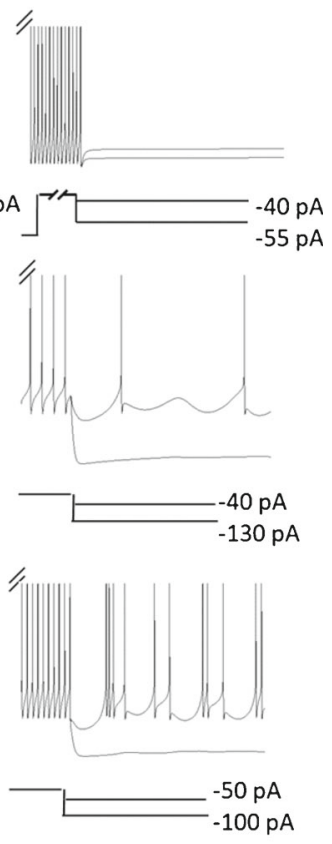

\section{Mouse cell}

Fig. 13 Cell transitions in response to an increasing amplitude hyperpolarizing current injection. Shown for comparison are two cells from the salamander and the mouse set, and experimental data (Margolis and Detwiler 2007). Cell responses are superimposed for different levels of current injection. Hyperpolarizing current produced different responses in different cells. Shown below each plot is the hyperpolarizing current levels used in the simulation. The same scale bar applies to all simulated plots. Salamander cell: In OFF S simulations, $\bar{g}_{\mathrm{NaP}}=$ $3.33 \times 10^{-6} \mathrm{~S} / \mathrm{cm}^{2}, \bar{g}_{\mathrm{T}}=5.36 \times 10^{-4} \mathrm{~S} / \mathrm{cm}^{2}$ and $\bar{g}_{\mathrm{h}}=10^{-5} \mathrm{~S} / \mathrm{cm}^{2} . \mathrm{In}$

Activation of $\mathrm{LVA} \mathrm{Ca}^{2+}$ current provides a mechanism that couples light offset to a precisely timed burst of spikes.

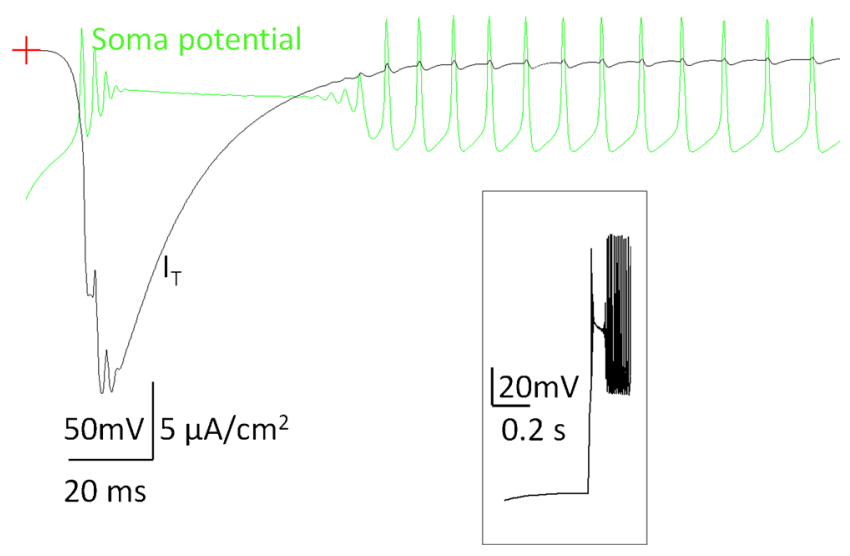

Fig. 14 Latent period at the termination of a hyperpolarizing current step. Shown is the soma membrane potential (green trace) and $I_{\mathrm{T}} \times 10^{5}$ (black trace) shown for comparison. Crosshair denotes the zero voltage point. The latent period is related to the inactivation time of $I_{\mathrm{T}}$ and can last anywhere between 20 and $80 \mathrm{~ms}$. Insert shows a soma membrane potential on a smaller time scale for better visualization
OFF T simulations, $\bar{g}_{\mathrm{NaP}}=2 \times 10^{-6} \mathrm{~S} / \mathrm{cm}^{2}, \bar{g}_{\mathrm{T}}=3.67 \times 10^{-4} \mathrm{~S} / \mathrm{cm}^{2}$ and $\bar{g}_{\mathrm{h}}=10^{-12} \mathrm{~S} / \mathrm{cm}^{2}$. Mouse cell: In OFF S simulations, $\bar{g}_{\mathrm{NaP}}=$ $6.67 \times 10^{-6} \mathrm{~S} / \mathrm{cm}^{2}, \bar{g}_{\mathrm{T}}=4.69 \times 10^{-4} \mathrm{~S} / \mathrm{cm}^{2}$ and $\bar{g}_{\mathrm{h}}=10^{-4} \mathrm{~S} / \mathrm{cm}^{2}$. In OFF T simulations, $\bar{g}_{\mathrm{NaP}}=10^{-15} \mathrm{~S} / \mathrm{cm}^{2}, \bar{g}_{\mathrm{T}}=4 \times 10^{-4} \mathrm{~S} / \mathrm{cm}^{2}$ and $\bar{g}_{\mathrm{h}}=10^{-6} \mathrm{~S} / \mathrm{cm}^{2}$. In both salamander and mouse ON simulations, $\bar{g}_{\mathrm{NaP}}=10^{-5} \mathrm{~S} / \mathrm{cm}^{2}, \bar{g}_{\mathrm{T}}=10^{-5} \mathrm{~S} / \mathrm{cm}^{2}$ and $\bar{g}_{\mathrm{h}}=10^{-5} \mathrm{~S} / \mathrm{cm}^{2}$. Experimental figures adapted from Margolis and Detwiler (2007) with permission

At the onset of light, OFF RGCs receive mostly inhibitory synaptic input from bipolar cells. Inward currents in dendrites (such as calcium currents) allow OFF cells to convert local inhibitory synaptic potential into an excitatory signal that robustly reaches the soma. ON cells, on the other hand, do not require such a mechanism to signal the light onset, which is triggered mostly by excitatory synaptic input.

Functional implications of LVA $\mathrm{Ca}^{2+}$ current signaling in other types of neurons are the focus of ongoing investigation (Destexhe et al. 1998). Dendritic LVA Ca ${ }^{2+}$ current plays an important role in the efficient modulation of thalamic burst discharges by corticothalamic feedback. Dendritic LVA $\mathrm{Ca}^{2+}$ current may explain differences in the intrinsic firing properties between thalamic reticular neurons recorded in-vitro and in-vivo (Destexhe et al. 1998).

It is important to examine the properties of the high density sodium channel band (SOCB) of the axon that was found in RGCs by Carras et al. (1992) and Fried et al. (2009), and others. It was shown previously that, in RGCs, the SOCB has the lowest threshold for electrical stimulation 
(Fried et al. 2009), and the effect of SOCB geometry and density on the cell's response to electrical stimulation was investigated computationally by Jeng et al. (2011). In some studies, the density of sodium channels was increased by 50 times over that of the soma in order to reproduce experimental results for pyramidal neurons (Kole et al. 2008).

In our modeling, the SOCB produced a low threshold region for action potential initiation. The absence of this higher density region $\left(\bar{g}_{\mathrm{Na}} R_{\mathrm{SOCB}, \text { soma }}=1\right)$ resulted in the low threshold region varying from cell to cell. In some cases, the low threshold region was present in dendritic compartments of the cell. This had the effect of producing unphysiological behavior in the soma and could not ensure orthodromic propagation of action potentials. Increasing the $\bar{g}_{\mathrm{Na}} R_{\mathrm{SOCB}}$,soma ensured that the low threshold region was always in the high density sodium region of the axon.

While our modeling was based on mice RGCs, it has been shown that intrinsic membrane currents in cells of primates are similar to those in lower vertebrates (Han et al. 2000). Also, our modeling did not distinguish between ionic channel subtypes. For example, it has been found that $\mathrm{Na}_{\mathrm{v}} 1.6$ and $\mathrm{Na}_{\mathrm{v}} 1.1$ are present in RGCs (Caldwell et al. 2000). However, how different activation thresholds of channel subtypes affects spiking properties of the cell was not investigated here. On the other hand, passive properties of the cell also shape action potential generation. In our models, all cells had the same axon geometry. How the length and diameter of axon affects action potentials is left for future studies.

This study sought to understand the effect of cell morphology on the mechanisms underlying differences between ON and OFF RGCs. An understanding of the mechanisms generating phenomena that are different for ON and OFF RGCs can assist in developing successful stimulation strategies for retinal implant devices. The models of ON and OFF RGCs developed here can be used to examine the possibility of differential stimulation of these cell classes by a visual prosthetic device. Since it was shown that ganglion cells are stable after degeneration-induced change in synaptic input (Margolis et al. 2010), our model may be adequate for describing this situation. Multicompartment models of RGCs may be used to investigate the effect of the stimulation electrode position on the threshold for firing, which is a crucial question for stimulation strategies for a successful visual implant.

How effectively synaptic and regenerative potentials propagate within neurons depends critically on the membrane properties and intracellular resistivity of the dendritic tree (Stuart and Spruston 1998). These properties can be examined using models such as ones described here by adding synaptic input. Also, it was shown that the noise in the dendrites has a large effect on the spike precision (van Rossum et al. 2003). Also, the bursting patterns vary substantially in the presence of noise (Channell et al. 2009). Our model can be extended to explore underlying mechanisms of these phenomena.

Dendritic shrinkage study of RGCs in cats with glaucoma showed that the cell soma size, total dendritic length, and number of branch bifurcations of dendrites decreased significantly in glaucomatous eyes compared with normal ones (Shou et al. 2003). How these changes in morphology affect the cell's capacity to fire action potentials can be investigated using multicompartment models such as those developed in this study.

Acknowledgments This research was supported by the Australian Research Council (ARC) through its Special Research Initiative (SRI) in Bionic Vision Science and Technology grant to Bionic Vision Australia (BVA). The Bionics Institute acknowledges the support it receives from the Victorian Government through its Operational Infrastructure Support Program. This research was supported by a Victorian Life Sciences Computation Initiative (VLSCI) grant number VR0138 on its Peak Computing Facility at the University of Melbourne, an initiative of the Victorian Government.

Open Access This article is distributed under the terms of the Creative Commons Attribution License which permits any use, distribution, and reproduction in any medium, provided the original author(s) and the source are credited.

\section{References}

Ascoli, G.A., Donohue, D.E., Halavi, M. (2007). NeuroMorpho.Org: a central resource for neuronal morphologies. Journal of Neuroscience, 27(35), 9247-9251.

Benison, G., Keizer, J., Chalupa, L.M., Robinson, D.W. (2001). Modeling temporal behavior of postnatal cat retinal ganglion cells. Journal of Theoretical Biology, 210, 187-199.

Caldwell, J.H., Schaller, K.L., Lasher, R.S., Peles, E., Levinson, S.R. (2000). Sodium channel Nav1.6 is localized at nodes of Ranvier, dendrites, and synapses. Proceedings of the National Academy of Sciences USA, 97, 5616-5620.

Carras, P.L., Coleman, P.A., Miller, R.F. (1992). Site of action potential initiation in amphibian retinal ganglion cells. Journal of Neurophysiology, 67(2), 292-304.

Channell, P., Fuwape, I., Neiman, A.B., Shilnikov, A.L. (2009). Variability of bursting patterns in a neuron model in the presence of noise. Journal of Computational Neuroscience, 27, 527-542.

Chen, L., \& Yang, X.L. (2007). Hyperpolarization-activated cation current is involved in modulation of the excitability of rat retinal ganglion cells by dopamine. Neuroscience, 150(2), 299308.

Coombs, J., van der List, D., Wang, G.Y., Chalupa, L.M. (2006). Morphological properties of mouse retinal ganglion cells. Journal of Neuroscience, 140(1), 123-136.

Destexhe, A., Neubig, M., Ulrich, D., Huguenard, J. (1998). Dendritic low-threshold calcium currents in thalamic relay cells. Journal of Neuroscience, 18(10), 3574-3588.

Fohlmeister, J.F., \& Miller, R.F. (1997). Mechanisms by which cell geometry controls repetitive impulse firing in retinal ganglion cells. Journal of Neurophysiology, 78(4), 1948-1964. 
Fried, S.I., Lasker, A.CW., Desai, N.J., Eddington, D.K. (2009). Axonal sodium-channel bands shape the response to electric stimulation in retinal ganglion cells. Journal of Neurophysiology, 101(4), 1972-1987.

Guenther, E., Schmid, S., Reiff, D., Zrenner, E. (1999). Maturation of intrinsic membrane properties in rat retinal ganglion cells. Vision Research, 39, 2477-2484.

Han, Y., Jacoby, R., Wu, S.M. (2000). Morphological and electrophysiological properties of dissociated primate retinal cells. Brain Research, 875, 175-186.

Henderson, D., \& Miller, R.F. (2007). Low-voltage activated calcium currents in ganglion cells of the tiger salamander retina: experiment and simulation. Visual Neuroscience, 24, 37-51.

Hines, M. (1993). NEURON a program for simulation of nerve equations In F. Eckman (Ed.), Neural systems: analysis and modeling. Norwell: Kluwer Academic Publishers.

Huguenard, J.R. (1996). Low-threshold calcium currents in central nervous system neurons. Annual Review of Physiology, 58, 329-348.

Jeng, J., Tang, S., Molnar, A., Desai, N.J., Fried, S.I. (2011). The sodium channel band shapes the response to electric stimulation in retinal ganglion cells. Journal of Neural Engineering, 8(3), e036022.

Kameneva, T., Meffin, H., Burkitt, A.N. (2011). Modelling intrinsic electrophysiological properties of ON and OFF retinal ganglion cells. Journal of Computational Neuroscience, 31(3), 547-561.

Kole, M.HP., Ilschner, S.U., Kampa, B.M., Williams, S.R., Ruben, P.C., Stuart, G.J. (2008). Action potential generation requires a high sodium channel density in the axon initial segment. Nature Neuroscience, 11(2), 178-186.

Lee, S.C., Hayashida, Y., Ishida, A.T. (2003). Availability of lowthreshold $\mathrm{Ca}^{2+}$ current in retinal ganglion cells. Journal of Neurophysiology, 90, 3888-3901.

Lee, S.C., \& Ishida, A.T. (2007). $\mathrm{I}_{h}$ without $\mathrm{K}_{i r}$ in adult rat retinal ganglion cells. Journal of Neurophysiology, 97, 3790-3799.

Llinas, R.R., \& Steriade, M. (2006). Bursting of thalamic neurons and states of vigilance. Journal of Neurophysiology, 95, 32973308.

Margolis, D.J., \& Detwiler, P.B. (2007). Different mechanisms generate maintained activity in $\mathrm{ON}$ and $\mathrm{OFF}$ retinal ganglion cells. Journal of Neuroscience, 27(22), 5994-6005.

Margolis, D.J., Gartland, A.J., Euler, T., Detwiler, P.H. (2010). Dendritic calcium signaling in $\mathrm{ON}$ and $\mathrm{OFF}$ mouse retinal ganglion cells. Journal of Neuroscience, 30(21), 7127-7138.

Mitra, P., \& Miller, R.F. (2007). Mechanism underlying rebound excitation in retinal ganglion cells. Visual Neuroscience, 24, 709-731.

Murphy, G.J., \& Rieke, F. (2006). Network variability limits stimulusevoked spike timing precision in retinal ganglion cells. Neuron, $52,511-524$.
Nelson, R., Famiglietti, E.V., Kolb, H. (1978). Intracellular staining reveals different levels of stratification for on-center and off-center ganglion cells in the cat retina. Journal of Neurophysiology, 41, 427-483.

O’Brien, B.J., Isayama, T., Richardson, R., Berson, D.M. (2002). Intrinsic physiological properties of cat retinal ganglion cells. Journal of Physiology, 538(3), 787-802.

Pang, J.-J., Gao, F., Wu, S.M. (2003). Light-evoked excitatory and inhibitory synaptic inputs to ON and OFF $\alpha$ ganglion cells in the mouse retina. Journal of Neuroscience, 23(14), 6063-6073.

Schiefer, M.A., \& Grill, W.M. (2006). Sites of neuronal excitation by epiretinal electrical stimulation. IEEE Transactions Neural System Rehabilitation. Engineering, 14(1), 5-13.

Sheasby, B.W., \& Fohlmeister, J.F. (1999). Impulse encoding across the dendritic morphologies of retinal ganglion cells. Journal of Neurophysiology, 81, 1685-1698.

Shou, T., Liu, J., Wang, W., Zhou, Y., Zhao, K. (2003). Differential dendritic shrinkage of alpha and beta retinal ganglion cells in cats with chronic glaucoma. Investigative Ophthalmology and Visual Science, 44(7), 3005-3010.

Stuart, G., \& Spruston, N. (1998). Determinants of voltage attenuation in neocortical pyramidal neuron dendrites. Journal of Neuroscience, 18(10), 3501-3510.

Sun, W., Li, N., He, S. (2002). Large-Scale morphological survey of mouse retinal ganglion cells. Journal of Comparative Neurology, $451,115-126$.

Toris, C.B., Eiesland, J.L., Miller, R.F. (1995). Morphology of ganglion cells in the neotenous salamander retina. Journal of Comparative Neurology, 352(4), 535-559.

Traub, R.D., Buhl, E.H., Gloveli, T., Whittington, M.A. (2003). Fast rhythmic bursting can be induced in layer 2.3 cortical neurons by enhancing persistent $\mathrm{NaP}$ conductance or by blocking $\mathrm{BK}$ channels. Journal of Neurophysiology, 89, 909-921.

Ullah, G., \& Schiff, S.J. (2010). Assimilating seizure dynamics. PLoS Computational Biology, 6(5).

van Drongelen, W., Koch, H., Elsen, F.P., Lee, H.C., Mrejeru, A., Doren, E., Marcuccilli, C.J., Hereld, M., Stevens, R.L., Ramirez, J.M. (2006). Role of persistent sodium current in bursting activity of mouse neocortical networks in vitro. Journal of Neurophysiology, 96, 2564-2577.

van Rossum, M.CW., OBrien, B.J., Smith, R.G. (2003). Effects of noise on the spike timing precision of retinal ganglion cells. Journal of Neurophysiology, 89, 2406-2419.

van Welie, I., Remme, M.WH., van Hooft, J., Wadman, W.J. (2006). Different levels of Ih determine distinct temporal integration in bursting and regular-spiking neurons in rat subiculum. Journal of Physiology, 576(1), 203-214.

Wang, X.J., Rinzel, J., Rogawski, M. (1991). A model of the T-type calcium current and the low-threshold spike in thalamic neurons. Journal of Neurophysiology, 66, 839-850. 